CIRJE-F-572

\title{
Habit Formation and the Present-Value Model of the Current Account: Yet Another Suspect
}

\author{
Takashi Kano \\ University of Tokyo \\ June 2008
}

CIRJE Discussion Papers can be downloaded without charge from:

http://www.e.u-tokyo.ac.jp/cirje/research/03research02dp.html

Discussion Papers are a series of manuscripts in their draft form. They are not intended for circulation or distribution except as indicated by the author. For that reason Discussion Papers may not be reproduced or distributed without the written consent of the author. 


\title{
Habit Formation and the Present-Value Model of the Current Account: Yet Another Suspect
}

\author{
Takashi $\mathrm{Kano}^{\dagger}$ \\ Graduate School of Economics \\ The University of Tokyo \\ 7-3-1 Hongo, Bunkyo-ku, Tokyo \\ 113-0033, JAPAN \\ Tel/fax: +81-3-5841-5655 \\ Email : tkano@e.u-tokyo.ac.jp \\ Current Draft: June 17, 2008
}

\begin{abstract}
A recent paper claims that habit formation in consumption plays an important role in current account fluctuations in selected developed countries, extending the present-value model of the current account (PVM) with consumption habits. In this paper, however, I show that the habit-forming PVM is observationally equivalent to the PVM augmented with persistent transitory consumption, which is induced by world real interest rate shocks. Based on a small open-economy real business cycle (SOE-RBC) model endowed with consumption habits as well as persistent world real interest rate shocks, this paper resolves the inherent identification problem of the habit-forming PVM by Bayesian methods to seek effects of habit formation on current account fluctuations in typical small open economies, Canada and the United Kingdom. Results reveal no clear evidence that habit formation plays a crucial role in current account fluctuations.
\end{abstract}

Key Words : Current account; Habit formation; World real interest rate; Present-value model; Small open economy model; Bayesian analysis.

JEL Classification Number: F32, F41, E32.

$\dagger$ This paper was circulated and presented as the paper entitled "Habit Formation, the World Real Interest Rate, and the Present Value Model of the Current Account." I would like to thank Jim Nason for research direction and discussion. I am also grateful to the editor Charles Engel, two anonymous referees, Jeannine Bailliu, Paul Beaudry, Paul Bergin, Hafedh Bouakez, Toni Braun, Mick Devereux, Shin-ichi Fukuda, Joe Gruber, Talan İscan, Shinsuke Ikeda, Kazuko Kano, Jinill Kim, Eric Leeper, Marc-André Letendre, Glenn Otto, Francisco Ruge-Murcia, Larry Schembri, and seminar and session participants at the Bank of Canada, Hosei University, Okayama University, University of Tokyo, Yokohama National University, the 2003 Canadian Economic Association Meeting, the 9th International Conference on Computing in Economics and Finance, the 2003 Fall Meeting of the Japanese Economic Association, and the 2007 Far Eastern Meetings of the Econometric Society for comments and suggestions. The paper receives financial supports from Nomura Foundation for Academic Promotion, Tokyo Marine Kagami Memorial Foundation, and KAKENHI (20730205). I am solely responsible for any errors and misinterpretations of this paper. 


\section{Introduction}

A small open-economy model endowed with rational, forward-looking economic agents serves as a benchmark for studying current account dynamics in the recent literature of openeconomy macroeconomics. This model, as known as the intertemporal approach to the current account or, more recently, a small open-economy real business cycle (SOE-RBC) model, stresses the consumption-smoothing behavior of economic agents in the determination of the current account in a small open economy 1 . When they expect changes in future income, forward-looking agents smooth their consumption by borrowing or lending in international financial markets and hence by generating current account movements. This role of consumption-smoothing behavior in current account determination is clearly expressed by the present-value model (PVM) of the current account, which is a closed-form solution of the canonical SOE-RBC model. For example, the PVM predicts that the current account of a small open economy moves into deficit when the economy's income is expected to decline temporarily, while no change in the current account occurs if the decline in income is expected to be permanent 2

Many empirical studies including Sheffrin and Woo (1990), Otto (1992), Ghosh (1995) and Bergin and Sheffrin (2000), however, fail to find empirical support for the standard PVM of the current account in postwar data of many of the G-7 economies. The cross-equation restrictions the standard PVM imposes on unrestricted vector autoregressions (VARs) are statistically rejected for all of the G-7 economies except the United States. Moreover, the forecasts of the standard PVM are too smooth to track actual current account movements. The empirical failures of the standard PVM have led some researchers to explore the role of consumption-tilting motives in current account movements: the current account might be adjusted to factors that deviate consumption away from the random-walk, permanent income level.

One way to introduce consumption-tilting motives into the standard SOE-RBC model is habit formation in consumption. Habit formation makes optimal consumption decisions of households depend not only on permanent income but also on past consumption. Habit-forming households tend to maintain their past consumption levels against unexpected shocks to permanent income; therefore, habit formation makes consumption smoother and more sluggish than in the basic permanent income hypothesis $(\mathrm{PIH})$. The sluggishness of consumption in turn implies more volatile current account movements than the standard PVM predicts. Gruber (2004) augments the otherwise standard PVM with consumption habits 3 Estimating a parameter capturing the degree of habit formation by GMM, he finds that consumption habits help improve the ability of the PVM to track actual current account movements in postwar quarterly G-7 data. He concludes that habit

\footnotetext{
${ }^{1}$ Obstfeld and Rogoff (1995) provide a most detailed survey of the intertemporal approach to the current account.

${ }^{2} \mathrm{~A}$ crucial prediction of the PVM is that only country-specific shocks matter for the current account of a small open economy. A global shock does not give a small open economy an opportunity to borrow or lend in international financial markets because all economies have identical preferences, technologies and endowments and hence react to a global shock symmetrically. For empirical tests of this prediction, see Glick and Rogoff (1995), İscan (2000), Nason and Rogers (2002), and Kano (2008).

${ }^{3} \mathrm{~A}$ similar modification of the standard PVM with consumption habits is also found in Bussière et al. (2004).
} 
formation plays an important role in current account dynamics.

Habit formation, however, is not the only source of the consumption-tilting behavior. For example, the stochastic world real interest rate introduces a consumption-tilting motive into the PVM of the current account. Expected changes in the world real interest rate tilt the optimal consumption path away from the random-walk, permanent income level and, as a result, create consumption-tilting in the PIH 4 Blankenau, Kose and Yi (2001) and Nason and Rogers (2006, hereafter NR) provide evidence that persistent world real interest rate shocks play a crucial role in explaining net trade balance/current account movements in small open economies. In particular, NR examine several economic factors in a canonical SOE-RBC model as "usual suspects" that might lead to the empirical failure of the standard PVM in postwar Canadian data. Among the suspects, which do not incorporate habit formation, their Bayesian Monte Carlo exercise shows that persistent world real interest rate shocks, when combined with an internalized risk premium in international financial markets, can explain the rejection of the standard PVM in Canadian data best.

In this paper, I show that the PVM augmented with habit formation (hereafter, the habitforming PVM) is observationally equivalent to a canonical PVM modified with an arbitrary transitory consumption component that follows an AR(1) process. The two PVMs, thus, imply the same time series of the current account. Perhaps more importantly, observational equivalence also holds between the habit-forming PVM and a PVM predicted by an SOE-RBC model with an AR(1) world real interest rate 5 Since the two PVMs, which are derived as closed-form solutions of different small open-economy models, yield identical sample statistics, tests of the habit-forming PVM are not informative for detecting the role of habit formation in current account movements; rather, statistics of the habit-forming PVM might capture effects of persistent world real interest rate shocks on current account fluctuations 6

The identification problem comes from the fact that the habit-forming PVM, as a partial equilibrium model, imposes no restrictions on the stochastic dynamics of net output growth. SOERBC models, on the other hand, impose restrictions on stochastic processes of both net output growth and the current account. This paper, hence, exploits restrictions of SOE-RBC models imposed on joint dynamics of net output growth and the current account to identify the role of habit formation in current account fluctuations. To do so, I add habit formation to NR's list of "usual suspects" by extending their model with consumption habits. I then investigate the extended model

\footnotetext{
${ }^{4}$ See Campbell and Mankiw (1989) for tests of the PIH, and Bergin and Sheffrin (2000) and Kano (2008) for tests of the current account PVM. In particular, Bergin and Sheffrin (2000) extend the standard PVM with stochastic variations in real interest rates as well as real exchange rates, which yield a serially-correlated transitory consumption component independent of permanent income. They observe that the extension improves the PVM's forecasts particularly in Australia and Canada.

${ }^{5}$ The list of other potential sources of transitory consumption shocks includes transitory government expenditure shocks affecting the utility function, real exchange rate shocks, and terms of trade shocks.

${ }^{6}$ In other words, tests of the habit-forming PVM potentially lead an econometrician to commit a Type II error by accepting the null hypothesis of habit formation when habit formation is a false specification of important consumption-tilting motives.
} 
by two Bayesian methods. In the first method, I estimate the extended SOE-RBC model nesting both habit formation and an $\mathrm{AR}(1)$ world real interest rate (hereafter, the Benchmark model) by applying a Bayesian posterior simulator to post-Bretton Woods data of two proto-type small open-economies, Canada and the United Kingdom 7 As in standard Bayesian posterior inferences of DSGE models exploited by Schorfheide (2000), Chang et al.(2002), and Bouakez and Kano (2006), this likelihood-based inference method lets actual data of Canada and the United Kingdom update researchers' prior on the two specifications of consumption dynamics, habit formation and persistent world real interest rate shocks. Deriving the posterior distributions of the parameters of habit formation and world real interest rate shocks, I infer which of the two mechanisms is more significant for current account fluctuations in the two small-open economies. Moreover, using degenerated prior distributions, I construct two more restrictive models that incorporate either of habits (hereafter, the Habit model) or the persistence of the world real interest rate (hereafter, the WRI model). After estimating the two alternative restrictive models, I compare the calculated marginal likelihoods of the three models in order to figure out how much habit formation and persistent world real interest rate shocks contribute to the overall statistical fit of the benchmark SOE-RBC model to actual data.

The second method, which is developed by DeJong et al.(1996) and Geweke (2007) and applied to the literature of SOE-RBC models by NR, treats Gruber's GMM statistics of the habitforming PVM as the selected "business-cycle moments" an SOE-RBC model needs to match. Taking into account uncertainty in the structural parameters with their posterior distributions estimated by the first method, I then simulate synthetic data with the Benchmark, Habit, and WRI models and construct the corresponding theoretical distributions of the moments of interest. Obtaining the empirical (posterior) distributions of Gruber's GMM moments based on a less-restrictive vector autoregression (VAR) with actual data of Canada and the United Kingdom, I choose one of the three SOE-RBC models that yields theoretical distributions overlapping with the empirical counterparts to a better degree as the underlying data generating process (DGP) of the current accounts in the two proto-type small open-economies.

Results of the Bayesian analysis in this paper reveal no evidence for an important role of habit formation in current account fluctuations. The following three observations strictly reject habit formation as a prime suspect of the observed excellent statistical fit of the habit-forming PVM. First, the estimated Benchmark model implies a negligibly small habit parameter but a large persistence of the world real interest rates. Second, the estimated Benchmark model dominates the estimated Habit model in terms of the overall statistical fit. Finally, as the third result, the estimated Benchmark model replicates Gruber's statistics of the habit-forming PVM quite successfully, while the estimated Habit model fails to mimic the empirical facts of the habit-forming PVM Gruber found through his empirical exercise.

The rest of this paper is organized as follows. Section 2 reviews the habit-forming PVM and discusses its observational equivalence problem. In section 3, the habit-forming PVM is estimated with the data of Canada and the United Kingdom to construct the empirical distributions of

\footnotetext{
${ }^{7}$ I am grateful to the editor Charles Engel for his suggestion of the first method.
} 
Gruber's GMM statistics. Section 4 introduces the SOR-RBC model in this paper and conducts the Bayesian analysis. Section 5 concludes.

\section{The habit-forming PVM and observational equivalence}

\subsection{The habit-forming PVM}

In this section, I introduce the habit-forming PVM this paper investigates and argue its observational equivalence property. Consider a small open-economy in which the representative household lives in infinite periods. To smooth consumption intertemporally, the representative household can access to incomplete international financial markets in which only state non-contingent riskless international bonds $B_{t}$ are traded under a constant world real interest rate $r$. Let $C_{t}$ and $N Y_{t}$ denote consumption and net output at period $t$ of the household, respectively. As in the standard literature, net output, which is defined by output $Y_{t}$ minus domestic investment $I_{t}$ minus government expenditure $G_{t}$, follows a nonstationary process with a country-specific, randomwalk technology shock as the driving force 8 While Gruber exploits a quadratic instantaneous utility function, this paper specifies the instantaneous utility function with the logarithmic form $u\left(C_{t+i}-h C_{t+i-1}\right) \equiv \ln \left(C_{t+i}-h C_{t+i-1}\right)$, where $0 \leq h<1$ represents the habit parameter 9 The expected discounted lifetime utility $E_{t} \sum_{i=0}^{\infty} \beta^{i} u\left(C_{t+i}-h C_{t+i-1}\right)$, where $E_{t}$ is the mathematical conditional expectation operator upon the representative agent's date $t$ information set and $0<\beta<1$ is the subjective discount factor, then implies that the representative household is habit-forming with respect to consumption. The one-period past level of consumption decreases the current level of utility, and only the current level of consumption over and above the habit level $h C_{t-1}$ effectively increases the current level of utility. The current and past levels of consumption, thus, are complements. This fact makes the habit-forming households averse to large swings in their consumption: the optimal consumption path becomes smoother than that predicted by a model with time-separable utility. As in Constantinides (1990), habit formation is specified as being internal where habits depend on the household's own consumption and the household takes habits into account when choosing the optimal amount of consumption 10

\footnotetext{
${ }^{8}$ The basic SOE-RBC model, which can be considered as a stochastically characterized version of the intertemporal approach to the current account, is a single-shock model containing a country-specific, unit-root technology shock: see Obstfeld and Rogoff (1995), Glick and Rogoff (1995), and NR. Under this assumption, the intertemporal approach has the standard PVM as a closed-form solution.

${ }^{9}$ There are two reasons that this paper adopts the log utility function. First, it will be explicitly shown below that under the log utility function, the habit-forming PVM is observationally equivalent to the PVM augmented with the stochastic world real interest rate. Second, the log utility function leads to a PVM with respect to the current account-net output ratio, while a quadratic utility function results in a PVM with respect to the level of the current account. This difference is very important for empirical investigation of PVMs that generally imply stationary current account series. It, however, is well known that the unit root null in the level of the current account is hard to be rejected with the standard unit root test in data of OECD economies. To the contrary, the null of a unit root in the current account-net output ratio is rejected more frequently. Furthermore, all the results of the habit-forming PVM shown below holds even user a more general constant elastic power utility function.

${ }^{10}$ On the other hand, as in Abel (1990) and Campbell and Cochrane (1999), habit formation is external or called
} 
The problem of the representative household is to maximize the lifetime utility function subject to the budget constraint $B_{t+1}=(1+r) B_{t}+N Y_{t}-C_{t}$. The optimality conditions for the maximizing problem consist of the Euler equation

$$
\left(C_{t}-h C_{t-1}\right)^{-1}-\beta h E_{t}\left(C_{t+1}-h C_{t}\right)^{-1}=\beta E_{t}\left[\left(C_{t+1}-h C_{t}\right)^{-1}-\beta h E_{t+1}\left(C_{t+2}-h C_{t+1}\right)^{-1}\right],
$$

and the budget constraint. The transversality condition $\lim _{i \rightarrow \infty} \beta^{i} E_{t}\left\{\lambda_{t+i} B_{t+1+i}\right\}=0$ must be satisfied for the sufficiency of the optimality, where $\lambda_{t}$ is a shadow price attached to the budget constraint. As shown in the appendix of Dynan (2000), if the real interest rate is constant, Euler equation (1) can be simplified as follows:

$$
\left(C_{t}-h C_{t-1}\right)^{-1}-\beta(1+r) E_{t}\left(C_{t+1}-h C_{t}\right)^{-1}=0 .
$$

This is because equation (11) implies that the LHS of the simplified Euler equation (2) is forward explosive.

To derive a closed-form solution of a current account measure, this paper follows the linear approximation exercise conducted by Kano (2008) and Bouakez and Kano (2008). The forward iteration of the budget constraint yields the intertemporal budget constraint

$$
\sum_{i=0}^{\infty}\left(\frac{1}{1+r}\right)^{i} E_{t} C_{t+i}=(1+r) B_{t}+\sum_{i=0}^{\infty}\left(\frac{1}{1+r}\right)^{i} E_{t} N Y_{t+i}
$$

The linear approximation exercise starts by dividing the intertemporal budget constraint by $N Y_{t}$ to obtain

$$
\begin{aligned}
\tau_{t}\left\{1+\sum_{i=1}^{\infty} E_{t}\left[\sum_{j=t+1}^{t+i} \exp \left(\sum_{j=t+1}^{i}\left(\Delta c_{j}-\mu\right)\right)\right]\right\} \\
=\exp \left(\mu-\Delta n y_{t}\right) b_{t}+\left\{1+\sum_{i=1}^{\infty} E_{t}\left[\sum_{j=t+1}^{t+i} \exp \left(\sum_{j=t+1}^{i}\left(\Delta n y_{j}-\mu\right)\right)\right]\right\},
\end{aligned}
$$

where $c_{t} \equiv \ln C_{t}, n y_{t} \equiv \ln N Y_{t}, \tau_{t} \equiv C_{t} / N Y_{t}, b_{t} \equiv B_{t} / N Y_{t-1}$, and $\mu \equiv \ln (1+r)$ are the $\log$ of consumption, the log of net output, the consumption-net output ratio, the bonds-net output ratio, and the log of the gross world real interest rate, respectively. The intertemporal budget constraint, then, is linearly approximated around the balanced growth path with a constant growth rate $\Delta c_{t}=\Delta n y_{t}=\alpha$. Let $\tau$ and $b$, respectively, denote the consumption-net output ratio and the international bonds-net output ratio on the balanced growth path. Furthermore, for any variable $x_{t}$, let $x_{t}^{*}$ denote the deviation of $x_{t}$ from its value on the balance growth path, $x$ (i.e., $x_{t}^{*}=x_{t}-x$ ). The linearly approximated intertemporal budget constraint then is given by

$$
\tau_{t}^{*}=\frac{1-\kappa}{\kappa}\left(b_{t}^{*}-b \Delta n y_{t}^{*}\right)+\sum_{i=1}^{\infty} \kappa^{i} E_{t} \Delta n y_{t+i}^{*}-\sum_{i=1}^{\infty} \kappa^{i} E_{t} \Delta c_{t+i}^{*},
$$

catching up with the Joneses if habits depend on aggregate consumption unaffected by any representative household decision. 
where we assume $\kappa=\exp (\alpha-\mu)<1,11$

In this paper, I also take a linear approximation of Euler equation (21) as follows. Notice that Euler equation (2) can be rewritten as

$$
\left[\exp \left(\Delta c_{t}\right)-h\right]^{-1} \exp \left(\Delta c_{t}\right)=\beta(1+r) E_{t}\left[\exp \left(\Delta c_{t+1}\right)-h\right]^{-1} .
$$

Assuming that $\beta(1+r)=1$ and taking the first-order Taylor expansion of this Euler equation around the balanced growth path together yield

$$
E_{t} \Delta c_{t+1}^{*}=h \Delta c_{t}^{*}
$$

Using this linearly-approximated Euler equation (44) then rewrites the linearly-approximated intertemporal budget constraint (3) as

$$
\tau_{t}^{*}=\frac{1-\kappa}{\kappa}\left(b_{t}^{*}-b \Delta n y_{t}^{*}\right)+\sum_{i=1}^{\infty} \kappa^{i} E_{t} \Delta n y_{t+i}^{*}-\frac{\tau \kappa h}{1-\kappa h} \Delta c_{t}^{*} .
$$

This paper defines the current account $C A_{t}$ conventionally by net trade plus net international interest payment: $C A_{t} \equiv r B_{t}+N Y_{t}-C_{t}$. Dividing the current account identity by $N Y_{t}$ provides $c a_{t}=1+\frac{\exp (\mu)-1}{\exp \left(\Delta n y_{t}\right)} b_{t}-\tau_{t}$, where $c a_{t} \equiv C A_{t} / N Y_{t}$ is the current account-net output ratio. Taking a linear approximation of the above equation around the balance growth path yields $c a_{t}^{*}=\left[\kappa^{-1}-\exp (-\alpha)\right]\left(b_{t}^{*}-b \Delta n y_{t}^{*}\right)-\tau_{t}^{*}$. Substituting equation (5) into $\tau_{t}^{*}$ in the linearlyapproximated current account identity and noting that $\exp (-\alpha)$ takes a value close to one lead to the following behavior function of the current account-net output ratio:

$$
c a_{t}^{*}=-\sum_{i=1}^{\infty} \kappa^{i} E_{t} \Delta n y_{t+i}^{*}+\frac{\tau \kappa h}{1-\kappa h} \Delta c_{t}^{*} .
$$

Equation (6) implies that the current account-net output ratio is determined by two factors. The first factor, which is captured by the first term of the RHS of equation (6), represents the consumption-smoothing behavior of the representative household. As in the standard PVM, this factor reflects the fact that the representative household smoothes income shocks by borrowing or lending in international financial markets. The second factor, which corresponds to the second term of the RHS in equation (6), is the consumption-tilting behavior of the representative household that is caused by habit formation. Habit formation makes the optimal consumption deviate from its smoothed level. Suppose that the growth rate of consumption rises at period $t$. Euler equation (44) implies that other things being equal, the household desires to keep the period $t+1$ consumption growth rate being positive. This requires that given the expected future path of net output, the household lends out in international financial markets today in order to finance the desired increase in consumption tomorrow. Therefore, the current account at period $t$ moves into surplus.

\footnotetext{
${ }^{11}$ The condition $\kappa<1$ is required to satisfy boundedness of expected discounted value terms of the linearly approximated intertemporal budget constraint (3). In the following analysis, this paper imposes this condition. Intuitively, this condition implies that on the balanced growth path the economy is dynamically efficient.
} 
as

Notice that with forecast error $v_{t+1}=\Delta c_{t+1}^{*}-E_{t} \Delta c_{t+1}^{*}$, Euler equation (44) can be rewritten

$$
\Delta c_{t+1}^{*}=h \Delta c_{t}^{*}+v_{t+1},
$$

where forecast error $v_{t+1}$ is orthogonal to the information set at period $t$, i.e., $E_{t} v_{t+1}=0$. Substituting equation (7) into equation (6) provides

$$
c a_{t}^{*}=-\sum_{i=1}^{\infty} \kappa^{i} E_{t} \Delta n y_{t+i}^{*}+\frac{\tau \kappa h}{1-\kappa h}\left(\Delta c_{t-1}^{*}+v_{t}\right) .
$$

Taking a lag of equation (6) and substituting the result back into the above equation lead to the habit-forming PVM of this paper

$$
c a_{t}^{*}=h c a_{t-1}^{*}+h \kappa \Delta n y_{t}^{*}-(1-h \kappa) \sum_{i=1}^{\infty} \kappa^{i} E_{t} \Delta n y_{t+i}^{*}+\epsilon_{t},
$$

where disturbance $\epsilon_{t}$ is given by $\epsilon_{t}=\frac{\tau h \kappa}{1-h \kappa} v_{t}-h \kappa \sum_{i=0}^{\infty}\left(E_{t}-E_{t-1}\right) \Delta n y_{t+i}^{*}$, which is serially uncorrelated and orthogonal to the date $t-1$ information set.

The habit-forming PVM of the current account-net output ratio, equation (8), corresponds to Gruber's habit-forming PVM with respect to the level of the current account (cf., equation 6 in Gruber 2004). In this case, the current account-net output ratio depends on its own past value. This makes the process of the current account more persistent than in the standard PVMs. Furthermore, the current account-net output ratio is sensitive to the current net output growth. This makes the current account-net output ratio more volatile compared to the standard PVM.

\subsection{Observational Equivalence}

In this paper, I claim that the habit-forming PVM (8) is observationally equivalent to a PVM augmented with an arbitrary transitory consumption component that follows an AR(1) process. To show the observational equivalence property of the habit-forming PVM (8), assume that $h=0$ in the utility function of the representative household. Notice that in this case, the optimal consumption-net output ratio consists only of the perfectly-smoothed, permanent-income level. The linearly approximated intertemporal budget constraint (5) then turns out to be

$$
\tau_{t, p}^{*}=\frac{1-\kappa}{\kappa}\left(b_{t}^{*}-b \Delta n y_{t}^{*}\right)+\sum_{i=1}^{\infty} \kappa^{i} E_{t} \Delta n y_{t+i}^{*},
$$

where $\tau_{t, p}^{*}$ is the perfectly-smoothed, permanent income level of the optimal consumption-net output ratio. Suppose that the observed consumption-net output ratio $\tau_{t}^{*}$ is decomposed into the perfectlysmoothed, permanent-income level $\tau_{t, p}^{*}$ and a transitory consumption component $\tau_{t, s}^{*}$, i.e., $\tau_{t}^{*}=$ $\tau_{t, p}^{*}+\tau_{t, s}^{*} 12$ Substituting the intertemporal budget constraint (9) into this decomposition and using

\footnotetext{
${ }^{12}$ Because the underlying SOE-RBC model has the unique stochastic trend, i.e. the country-specific, permanent, technology shock, it is possible to decompose consumption into a random-walk, permanent-income component and a transitory component: see King, Plosser and Rebelo (1988).
} 
the linearly-approximated current account identity provides

$$
c a_{t}^{*}=-\tau_{t, s}^{*}-\sum_{i=1}^{\infty} \kappa^{i} E_{t} \Delta n y_{t+i}^{*} .
$$

Suppose that the transitory component of the consumption-net output ratio follows an $\operatorname{AR}(1)$ process $\tau_{t, s}^{*}=\rho \tau_{t-1, s}^{*}+a_{t}$ where $0<\rho<1$ and $a_{t}$ is serially uncorrelated and orthogonal to the information set at period $t-1$. Substituting the AR(1) process of the transitory consumption-net output ratio into the above current account-net output equation results in the following PVM:

$$
c a_{t}^{*}=\rho c a_{t-1}^{*}+\rho \kappa \Delta n y_{t}^{*}-(1-\rho \kappa) \sum_{i=1}^{\infty} \kappa^{i} E_{t} \Delta n y_{t+i}^{*}+z_{t},
$$

where $z_{t}$ is a serially uncorrelated disturbance such that $z_{t}=-a_{t}-\rho \kappa \sum_{i=0}^{\infty} \kappa^{i}\left(E_{t}-E_{t-1}\right) \Delta n y_{t+i}^{*}$. Note that $z_{t}$ is orthogonal to the date $t-1$ information set.

Given expectations of future changes in net output, when $h=\rho$, the habit-forming PVM (8) and the PVM with a transitory consumption component following an AR(1) process, equation (10), imply identical time-series properties of the current account-net output ratio. This fact means that the two PVMs impose the same cross-equation restrictions on an unrestricted VAR - the two PVMs, therefore, are observationally equivalent. To see this more precisely, assume that the joint dynamics of net output growth and the current account-net output ratio are well approximated by a $p$ th-order VAR (hereafter, I also express a VAR by model $\mathcal{M}_{0}$ ): $Y_{t}=A_{1} Y_{t-1}+A_{2} Y_{t-2}+\cdots+$ $A_{p} Y_{t-p}+v_{t}$, where $Y_{t}$ is the information set that includes the first difference of the log of net output, $\Delta n y_{t}^{*}$, and the current account-net output ratio $c a_{t}^{*}$ as a part of the elements, and $v_{t}$ is an i.i.d. normally distributed disturbance vector with mean zero and a symmetric positive definite variancecovariance matrix $\Sigma$. Let $\mathcal{A}$ denote a companion matrix of a first-order representation of the $p$ thorder VAR: $\mathcal{Y}_{t}=\mathcal{A} \mathcal{Y}_{t-1}+u_{t}$ where $\mathcal{Y}_{t}=\left[\begin{array}{lllll}Y_{t}^{\prime} & Y_{t-1}^{\prime} & \cdots & Y_{t-p+1}^{\prime}\end{array}\right]^{\prime}$ and $u_{t}=\left[\begin{array}{llll}v_{t}^{\prime} & 0 & \cdots & 0\end{array}\right]^{\prime}$. Suppose that $\Delta n y_{t}^{*}$ and $c a_{t}^{*}$ are the $i$ th and $j$ th elements of vector $Y_{t}$, respectively. As shown in Appendix 1, the habit-forming PVM (8) then implies the following forecast of the current accountnet output ratio, $c a_{t}^{f}$,

$$
c a_{t}^{f} \equiv \mathcal{H}(h, \mathcal{A} ; \kappa) Y_{t}=\left\{(1-h) \mathbf{e}_{j}+\left[\mathbf{e}_{j}-h \kappa \mathbf{e}_{i}+(1-h \kappa) \mathbf{e}_{i} \kappa \mathcal{A}(I-\kappa \mathcal{A})^{-1}\right] \mathcal{A}\right\} Y_{t},
$$

where $\mathbf{e}_{i}$ is the $1 \times n(p-1)$ row vector such that the $i$ th element is one and all the other elements are zero. If the habit-forming PVM (8) holds in data, the model's forecast of the current account-net output ratio must equal the actual one, i.e., $c a_{t}^{f}=c a_{t}^{*}$. This means that under the null, row vector $\mathcal{H}(h, \mathcal{A} ; \kappa)$ should contain one as the $j$ th element and zeros as all the other elements: $\mathcal{H}(h, \mathcal{A} ; \kappa)=\mathbf{e}_{j}$. Appendix 1 also discusses that the PVM with a transitory consumption component, equation (10), imposes cross-equation restrictions $\mathcal{H}(\rho, \mathcal{A} ; \kappa)=\mathbf{e}_{j}$ on the unrestricted VAR. When $h=\rho$, the two PVMs, therefore, imply the same likelihood value of the VAR restricted by the identical crossequation restrictions. In this sense, the two PVMs are observationally equivalent.

\subsection{An example: the PVM with persistent world real interest rate shocks}


One of the most important candidates for the transitory consumption component in the literature of the current account is the stochastic slow-moving world real interest rate, as emphasized by NR with their Bayesian Monte Carlo exercise based on an SOE-RBC model. In this subsection, I show that the habit-forming PVM (8), indeed, is observationally equivalent to the PVM augmented with persistent world real interest rate shocks, when the world real interest rate $r_{t}$ follows an $\operatorname{AR}(1)$ process, $r_{t}=\left(1-\rho_{r}\right) r+\rho_{r} r_{t-1}+w_{t}$, where $0<\rho<1$ and $w_{t}$ is serially uncorrelated.

As observed by Kano (2008) and Bouakez and Kano (2008), if the instantaneous utility is time separable (i.e., $h=0$ ) and the world real interest rate is allowed to vary stochastically, the current account-net output ratio has a linearly approximated closed-form solution such that

$$
c a_{t}^{*}=b r_{t}^{*}+\sum_{i=1}^{\infty} \kappa^{i} E_{t} r_{t+i}^{*}-\sum_{i=1}^{\infty} E_{t} \Delta n y_{t+i}^{*} .
$$

Notice that the $\mathrm{AR}(1)$ process of the world real interest rate rewrites this behavior function of the current account-net output ratio as $c a_{t}^{*}=r_{t}^{*}-\sum_{i=1}^{\infty} \kappa^{i} E_{t} \Delta n y_{t+i}^{*}$ where $\gamma=b+\kappa \rho_{r}\left(1-\kappa \rho_{r}\right)^{-1}$. It then is straight-forward to see that applying the $\operatorname{AR}(1)$ process of the world real interest to this behavior function of the current account-net output ratio produces

$$
c a_{t}^{*}=\rho_{r} c a_{t-1}^{*}+\rho_{r} \kappa \Delta n y_{t}^{*}-\left(1-\rho_{r} \kappa\right) \sum_{i=1}^{\infty} \kappa^{i} E_{t} \Delta n y_{t+i}^{*}+z_{t}^{r},
$$

where $z_{t}^{r}$ is a serially uncorrelated disturbance such that $z_{t}^{r}=\gamma w_{t}-\rho_{r} \kappa \sum_{i=0}^{\infty} \kappa^{i}\left(E_{t}-E_{t-1}\right) \Delta n y_{t+i}^{*}$. Observe the equivalence between the habit-forming PVM (8) and the PVM augmented with persistent world real interest rate shocks (12) when $h=\rho_{r}$.

\section{Reality of the habit-forming PVM in small open-economies}

Before approaching the identification problem, I show how the habit-forming PVM (8) fits to actual current account data in this section. The generalized method of moments (GMM) estimator Gruber proposes provides a consistent estimate of habit parameter $h$ conditional on the habit-forming PVM. To construct the GMM estimator, define a new variable $d_{t}$ by $d_{t} \equiv$ $c a_{t}^{*}-\Delta n y_{t}^{*}-\kappa^{-1} c a_{t-1}^{*}$, where $\kappa=0.9936$ is calculated from calibration $\alpha=0.0033$ and $\mu=0.0071 .13$ As shown in Appendix 2, the habit-forming PVM implies that variable $d_{t}$ follows a stochastic process $d_{t}=h d_{t-1}+\epsilon_{t}-\kappa^{-1} \epsilon_{t-1}+e_{t}$, where $e_{t}$ is orthogonal to the information set at period $t-1$. This fact in turn means unconditional moment conditions $E W_{t-2} \otimes\left(d_{t}-h d_{t-1}\right)=0$, where $E$ is the mathematical unconditional expectation operator, $W_{t-2}$ is a $p \times 1$ vector containing instrument variables in the information set at period $t-2$, and $\otimes$ is the mathematical operator of the Kronecker product. Following Gruber, I include $\Delta n y_{t-3}, c a_{t-3}, \Delta n y_{t-4}$, and $c a_{t-4}$ in instrument

\footnotetext{
${ }^{13}$ The balanced growth rate $\alpha$ is calibrated to match to the sample mean of the quarterly Canadian net output growth rate. The calibrated value of the constant world real interest rate, $\mu$, comes from the prior mean of the constant real interest rate used in NR.
} 
vector $W_{t-2}$. These unconditional moment conditions make it possible to estimate habit parameter $h$ by GMM. In particular, I use the two-step, two-stage least square (2S-2SLS) estimator applying the Newey-West (1987) covariance matrix estimator to the optimal weighting matrix in the second stage 14 The 2S-2SLS procedure provides the point estimate of the habit parameter, $\hat{h}$, and the corresponding Hansen's (1982) J statistic $\hat{\mathcal{J}}$ for testing overidentifying restrictions. Under the null of the orthogonality of $d_{t}-h d_{t-1}$ to $W_{t-2}$, statistic $\hat{\mathcal{J}}$ is asymptotically distributed with the $\chi^{2}$ function with degree of freedom $p-1$.

Given an $n \times 1$ column vector of data, $Y_{t}$, I simulate the posterior distributions of the population means of habit parameter $h$, J statistic $\mathcal{J}$, cross-equation restrictions $\mathcal{H}$, and forecast of the current account-net output ratio $c a_{t}^{f}$ by using a Bayesian posterior simulation method 15 To derive the posterior distributions of the population means, I exploit the $p$ th-order VAR of $Y_{t}$. Let $\mathcal{M}_{0}$ denote the VAR. The population means of $h$ and $\mathcal{J}$, which are respectively denoted by $\mathbf{m}_{h}$ and $\mathbf{m}_{J}$, are obtained as the mathematical means of the 2S-2SLS estimates conditional on the VAR: $\mathbf{m}_{h}=E\left(\hat{h} \mid \mathcal{M}_{0}\right)$ and $\mathbf{m}_{J}=E\left(\hat{\mathcal{J}} \mid \mathcal{M}_{0}\right)$. The population mean of vector $\mathcal{H}$, which is denoted by $\mathbf{m}_{\mathcal{H}}$, is given as the mathematical conditional mean $\mathbf{m}_{\mathcal{H}}=E\left(\hat{\mathcal{H}} \mid \mathcal{M}_{0}\right)$. Similarly, the model's forecast of the current account-net output ratio, which is denoted by $\mathbf{m}_{c a, t}$, is aquired as the mathematical mean of $c a_{t}^{f}$ conditional on the VAR and the time $t$ information set: $\mathbf{m}_{c a, t}=E\left(\hat{\mathcal{H}} \mid \mathcal{M}_{0}\right) Y_{t}$.

Let $p\left(\mathbf{m}_{h} \mid \mathbf{Y}, \mathcal{M}_{0}\right), p\left(\mathbf{m}_{J} \mid \mathbf{Y}, \mathcal{M}_{0}\right), p\left(\mathbf{m}_{\mathcal{H}} \mid \mathbf{Y}, \mathcal{M}_{0}\right)$, and $p\left(\mathbf{m}_{c a, t} \mid \mathbf{Y}, \mathcal{M}_{0}\right)$ denote the posterior probability densities of $\mathbf{m}_{h}, \mathbf{m}_{J}, \mathbf{m}_{\mathcal{H}}$, and $\mathbf{m}_{c a, t}$ conditional on the whole data $\mathbf{Y}=\left\{Y_{t}\right\}_{t=1}^{T}$ and the $\operatorname{VAR} \mathcal{M}_{0}$. The posterior joint density of the $\operatorname{VAR}$ parameters is given by $p(\mathcal{A}, \Sigma \mid \mathbf{Y}) \propto$ $p(\mathcal{A}, \Sigma) p(\mathbf{Y} \mid \mathcal{A}, \Sigma)$, where $p(\mathcal{A}, \Sigma)$ and $p(\mathbf{Y} \mid \mathcal{A}, \Sigma)$ are the prior joint density of the VAR parameters and the probability density of $\mathbf{Y}$ conditional on the VAR parameters (i.e., the likelihood of $\mathbf{Y}$ ), respectively. Notice that given the VAR, variables $d_{t}$ and $W_{t-2}$ can be drawn from the joint density $p\left(d_{t}, W_{t-2} \mid \mathcal{A}, \Sigma\right)$ by a Monte Carlo simulation. Furthermore, recall that statistics $\hat{h}$ and $\hat{\mathcal{J}}$ are functions of $\mathbf{d}=\left\{d_{t}\right\}_{t=1}^{T}$ and $\mathbf{W}=\left\{W_{t-2}\right\}_{t=3}^{T}: \hat{h}=\hat{h}(\mathbf{X})$ and $\hat{\mathcal{J}}=\hat{\mathcal{J}}(\mathbf{X})$ where $\mathbf{X}=[\mathbf{d}, \mathbf{W}]$. This consideration then leads to the following Bayesian Monte Carlo integration to approximate the posterior densities of $\mathbf{m}_{h}, \mathbf{m}_{J}, \mathbf{m}_{\mathcal{H}}$, and $\mathbf{m}_{c a, t}$ conditional on the VAR:

$$
\begin{gathered}
p\left(\mathbf{m}_{h} \mid \mathbf{Y}, \mathcal{M}_{0}\right)=\int_{\Sigma} \int_{\mathcal{A}} \int_{\mathbf{X}} \hat{h}(\mathbf{X}) p(\mathbf{X} \mid \mathcal{A}, \Sigma) p(\mathcal{A}, \Sigma \mid \mathbf{Y}) \partial \mathbf{X} \partial \mathcal{A} \partial \Sigma \\
p\left(\mathbf{m}_{J} \mid \mathbf{Y}, \mathcal{M}_{0}\right)=\int_{\Sigma} \int_{\mathcal{A}} \int_{\mathbf{X}} \hat{\mathcal{J}}(\mathbf{X}) p(\mathbf{X} \mid \mathcal{A}, \Sigma) p\left(\mathcal{A}, \Sigma \mid Y^{T}\right) \partial \mathbf{X} \partial \mathcal{A} \partial \Sigma \\
p\left(\mathbf{m}_{\mathcal{H}} \mid \mathbf{Y}, \mathcal{M}_{0}\right)=\int_{\Sigma} \int_{\mathcal{A}} \int_{\mathbf{X}} \mathcal{H}(\hat{h}(\mathbf{X}), \mathcal{A} ; \kappa) p(\mathbf{X} \mid \mathcal{A}, \Sigma) p\left(\mathcal{A}, \Sigma \mid Y^{T}\right) \partial \mathbf{X} \partial \mathcal{A} \partial \Sigma
\end{gathered}
$$

and

$$
p\left(\mathbf{m}_{c a, t} \mid \mathbf{Y}, \mathcal{M}_{0}\right)=\left\{\int_{\Sigma} \int_{\mathcal{A}} \int_{\mathbf{X}} \mathcal{H}(\hat{h}(\mathbf{X}), \mathcal{A} ; \kappa) p(\mathbf{X} \mid \mathcal{A}, \Sigma) p\left(\mathcal{A}, \Sigma \mid Y^{T}\right) \partial \mathbf{X} \partial \mathcal{A} \partial \Sigma\right\} Y_{t} .
$$

\footnotetext{
${ }^{14}$ The detailed description of the 2S-2SLS estimator is found in Davidson and MacKinnon (1993, p599).

${ }^{15}$ By focusing on the population means of statistics $h, \mathcal{J}, c a_{t}^{f}$, and $\mathcal{H}$, instead of the statistics themselves, I follow the minimal econometric interpretation of DSGE models formalized by Geweke (2007). This interpretation requires an athoretical statistical model that yields the posterior distributions of unobservable population moments of statistics of interest. I exploit a VAR as such a statistical model.
} 
In this paper, I scrutinize post-Bretton Woods data of Canada and the United Kingdom. The data span the period Q1:1973-Q2:2005 for Canada and Q1:1973-Q4:2003 for the United Kingdom. All data are real and seasonally adjusted at annual rates 16 Data vector $Y_{t}$ includes the first difference of the log of net output, $\Delta n y_{t}$, and the current account-net output ratio $c a_{t}$ as well as the $\log$ of the consumption-output ratio, $c_{t}-y_{t}: Y_{t}=\left[\Delta n y_{t}, c_{t}-y_{t}, c a_{t}\right]^{\prime}$. This specific information set is chosen because consumption data might provide better identification of habit formation: habit formation should have strong implications on consumption dynamics. Given a prior distribution constructed by the OLS estimates, the posterior joint density of $\operatorname{VAR}(2)$ parameters, $p(A, \Sigma \mid \mathbf{Y})$, are simulated with 5,000 Markov chain Monte Carlo draws generated by a Metropolis-Hastings algorithm 17 For each posterior draw of the VAR parameters, I simulate 100 series of vector $\mathbf{X}$ and calculate 100 sets of statistics $\hat{h}, \hat{\mathcal{J}}, \hat{\mathcal{H}}$, and $\left\{c a_{t}^{f}\right\}_{t=1}^{T}$. A posterior draw of the set of population means $\mathbf{m}_{h}, \mathbf{m}_{J}, \mathbf{m}_{\mathcal{H}}$, and $\left\{\mathbf{m}_{c a, t}\right\}_{t=1}^{T}$ is approximated by taking the average of the 100 sets of $\hat{h}$, $\hat{\mathcal{J}}, \hat{\mathcal{H}}$, and $\left\{c a_{t}^{f}\right\}_{t=1}^{T}$. I repeat this process for the 5,000 posterior draws of the VAR parameters to construct the posterior distributions of population means, $\mathbf{m}_{h}, \mathbf{m}_{J}, \mathbf{m}_{\mathcal{H}}$ and $\left\{\mathbf{m}_{c a, t}\right\}_{t=1}^{T}$.

Figure 1 plots non-parametrically smoothed estimates of the posterior densities of the population means of the habit parameter and the J statistics, $p\left(\mathbf{m}_{h} \mid \mathbf{Y}, \mathcal{M}_{0}\right)$ and $p\left(\mathbf{m}_{J} \mid \mathbf{Y}, \mathcal{M}_{0}\right)$ for the two economies 18 As the two windows in the first row show, the Canadian posterior means of $\mathbf{m}_{h}$ and $\mathbf{m}_{J}$ are 0.708 and 17.658, which are accompanied by 90 percent Bayesian credible intervals $[0.384,0.957]$ and $[8.941,30.254]$, respectively. Therefore, one might conclude that the habit parameter is strictly positive and less than 1 , although the overidentifying restrictions are likely to be rejected as implied by the 90 percent credible interval of $\mathbf{m}_{J}$, which is greater than the critical value of 7.820 for the 5 percent-size test based on the $\chi^{2}$ statistic with the third degree of freedom. Next the two windows in the second row exhibit that in the United Kingdom, the posterior means of $\mathbf{m}_{h}$ and $\mathbf{m}_{J}$ are 0.288 and 8.423 , which are accompanied by 90 percent Bayesian credible intervals $[-0.040,0.624]$ and $[4.175,13.262]$, respectively. Although the population mean of the habit parameter is less precisely inferred to be smaller than that in the Canadian data, the data of the United Kingdom, conditional on the habit-forming PVM, assign a large mass posterior probability to the positive interval of the habit parameter. Moreover, as implied by the 90 percent credible interval of $\mathbf{m}_{J}$, the overidentifying restrictions are unlikely to be rejected under the critical value of 7.820 for the 5 percent-size test with the third degree of freedom 19

Figure 2 summarizes the posterior inference on the population mean of the forecast of the current account-net output ratio, $\mathbf{m}_{c a, t}$. The upper-left window in the figure depicts the posterior

\footnotetext{
${ }^{16}$ Appendix 3 provides the detailed description of the source and construction of the data used in this paper.

${ }^{17}$ This paper uses John Geweke's BACC software to generate the posterior joint distribution of the VAR parameters $A$ and $\Sigma$. The software is available at http://www2.cirano.qc.ca/bacc/bacc2003/. The second order is selected as the optimal lag length because the $\operatorname{VAR}(2)$ yields the highest marginal likelihood among VARs with different orders.

${ }^{18}$ Following NR, I use the normal kernel and the automatic bandwidth proposed by Silverman (1986) in the nonparametric smoothed estimation of the posterior densities.

${ }^{19}$ In his sample of Canada and the United Kingdom, which span the period Q2:1958-Q3:2002, Gruber reports the point estimate of the habit parameter of 0.775 with the standard error of 0.335 and the corresponding $\mathrm{J}$ statistic of 7.731 for Canada, and the point estimate of the habit parameter of 0.550 with the standard error of 0.427 and the corresponding J statistic of 1.928 for the United Kingdom, respectively.
} 
mean of $\mathbf{m}_{c a, t}$ (the green line) as well as the actual current account-net output ratio (the blue line) of the Canadian sample. The striking observation is that the posterior mean can track the actual current account-net output ratio very precisely. The upper-right window plots the 5 and 95 percentiles of the pointwise posterior distributions of $\mathbf{m}_{c a, t}$. The reported 90 percent Bayesian credible intervals are quite narrow and include the actual data points in almost all quarters in the sample. The result of the excellent forecast ability of the habit-forming PVM, however, does not necessarily implies that the posterior mean of $\mathbf{m}_{\mathcal{H}}$ in equation (11) is equal to the hypothetical one under the null of the habit-forming PVM (8) , i.e., $\mathbf{e}_{3}=[0.000,0.000,1.000,0.000,0.000,0.000]$. In fact, the posterior mean of $\mathbf{m}_{\mathcal{H}}$ is $[0.161,0.450,0.954,0.159,-0.403,0.139]$ with the standard deviation of $[0.073,0.186,0.103,0.040,0.090,0.059]$. Thus, the cross-equation restrictions of the habit-forming PVM, particularly with respect to the second, fourth, and fifth elements of vector $\mathcal{H}$, are far from their hypothetical counterparts. Similarly, the lower-left window shows the posterior mean of $\mathbf{m}_{c a, t}$ as well as the actual current account-net output ratio for the United Kingdom. As in the case of Canada, the posterior mean can track the actual current account-net output ratio precisely. The lower-right window reveals that in the United Kingdom, the 5 and 95 percentiles of the pointwise posterior distributions of $\mathbf{m}_{c a, t}$ create narrow 90 percent credible intervals which contain the actual data points in the entire sample period. The posterior mean of $\mathbf{m}_{\mathcal{H}}$ for the United Kingdom is $[0.095,-0.155,1.005,0.049,-0.108,0.112]$ with the standard deviation of $[0.076,0.407,0.126,0.039,0.139,0.068]$. In the data of the United Kingdom, the cross-equation restrictions of the habit-forming PVM, therefore, are fairly consistent with the hypothetical values under the null, i.e., $[0.000,0.000,1.000,0.000,0.000,0.000]$.

Overall, the above results from the data of the two proto-type small open-economies imply that the habit-forming PVM does a fairly good job in explaining the current account fluctuations, although more stringent piecewise tests of the theoretical restrictions are against the model in the Canadian data. In fact, the data of the United Kingdom strongly support the cross-equation restrictions of the habit-formation PVM, while the habit parameter is identified poorly. These are consistent with the observations of Gruber.

It should be recalled, however, that because of the zero-power property of the GMM statistics based on the habit-forming PVM, its good fit to the data is not necessarily attributed to habit formation; i.e., the persistence of the world real interest rate imply the identical dynamics of the current account-net output ratio, given expectations of future changes in the log of net output. The habit-forming PVM fails to identify the role habit formation plays in current account fluctuations separately from the effects of persistent world real interest rate shocks. The reason is simple: this partial equilibrium model imposes no restriction on the stochastic process of net output growth jointly with that of the current account. As the next section shows, notice that in SOE-RBC models nesting the habit-forming PVM, habit formation and persistent world real interest rate shocks might have different implications on investment, hours worked, output, and net output. This means that additional restrictions an SOE-RBC model with habits impose on net output growth might lead to identification of the role of habits in current account fluctuations. 


\section{Identification of habit formation with an SOE-RBC model}

\subsection{An SOE-RBC model with habit formation}

In this section, I introduce the SOE-RBC model this paper uses for identifying habit formation in consumption. The model is the SOE-RBC model of NR augmented by habit formation in consumption. Let $N_{t}$ denote hours worked of the representative household at period $t$. The lifetime utility of the habit-forming household then is

$$
U_{t}=E_{t} \sum_{i=0}^{\infty} \beta^{i}\left[\phi \ln \left(C_{t+i}-h C_{t+i-1}\right)+(1-\phi) \ln \left(1-N_{t+i}\right)\right], 0 \leq h<1,0<\phi<1 .
$$

Equation (13) implies that the lifetime utility is separable between consumption and leisure in each period. NR observe that non-separability of utility between consumption and leisure is not crucial for explaining the standard PVM's forecasts of the Canadian current account. Following their observation, this paper assumes the logarithmic instantaneous utility function separable over consumption and leisure.

Let $r_{t}$ denote the time-varying real interest rate the representative household faces at period $t$, respectively. The household's budget constraint is

$$
B_{t+1}=\left(1+r_{t}\right) B_{t}+Y_{t}-I_{t}-G_{t}-C_{t} .
$$

Output $Y_{t}$ is produced by a Cobb-Douglas production function

$$
Y_{t}=K_{t}^{\psi}\left[A_{t} N_{t}\right]^{1-\psi} \quad 0<\psi<1,
$$

where $K_{t}$ and $A_{t}$ are the stock of capital and the level of county-specific, labor-augmenting technology at period $t$. The law of motion of capital is represented by

$$
K_{t+1}=(1-\delta) K_{t}+\left(\frac{K_{t}}{I_{t}}\right)^{\varphi} I_{t}, \quad 0<\varphi, \quad 0<\delta<1,
$$

where $\delta$ is the depreciation rate. Equation (16) includes capital adjustment costs with parameter $\varphi: \varphi$ is the inverse of the price elasticity of the investment-capital ratio.

As studied by NR and Schmitt-Grohé and Uribe (2003), the stochastic real interest rate $r_{t}$ is decomposed into two components. The first component $q_{t}$ is the unique, exogenous stochastic rate of return common across economies around the world. In this paper, $q_{t}$ follows a covariance stationary process. The second component is a risk premium specific to this small open economy. The risk premium is given as a linear function of the economy's bond-output ratio. This paper, hence, specifies the stochastic real interest rate $r_{t}$ as

$$
r_{t}=q_{t}-\eta \frac{B_{t}}{Y_{t}}, \quad 0<\eta .
$$


Equation (17) implies that if the small open economy is a debtor (i.e. $B_{t}<0$ ), the economy must pay a premium above $q_{t} 20$ Furthermore, as in NR, this paper assumes that the representative household internalizes the effect of a change in the bond-output ratio on the country-specific risk premium. The result of NR strongly supports the internalized risk premium as an important mechanism for explaining the standard PVM's rejection in the Canadian current account. This is because the internalized risk premium shuts off the consumption-smoothing role of employment adjustments, which is not captured by the standard PVM.

The processes of the three exogenous impulses, $G_{t}, A_{t}$, and $q_{t}$, are specified as follows. Government consumption expenditure $G_{t}$ is proportional to output $Y_{t}$ with a stochastic, timevarying ratio $g_{t}=G_{t} / Y_{t} 21$ The stochastic transitory component of government expenditure, $g_{t}$, follows an $\mathrm{AR}(1)$ process in the logarithmic term:

$$
\ln g_{t}=\left(1-\rho_{g}\right) \ln g^{*}+\rho_{g} \ln g_{t-1}+\epsilon_{t}^{g} \quad\left|\rho_{g}\right|<1, \quad \epsilon_{t}^{g} \sim \text { i.i.d.N }\left(0, \sigma_{g}^{2}\right) .
$$

The log of the country-specific, labor-augmenting technology $A_{t}$ is a random-walk with a drift

$$
A_{t}=A_{t-1} \exp \left(\alpha+\epsilon_{t}^{a}\right), \quad \alpha>0, \quad \epsilon_{t}^{a} \sim \text { i.i.d.N }\left(0, \sigma_{a}^{2}\right) .
$$

Finally, the gross world real interest rate $1+q_{t}$ follows an $\mathrm{AR}(1)$ process in the logarithmic term

$$
\ln \left(1+q_{t}\right)=\left(1-\rho_{q}\right) \ln \left(1+q^{*}\right)+\rho_{q} \ln \left(1+q_{t-1}\right)+\epsilon_{t}^{q}, \quad\left|\rho_{q}\right|<1, \quad \epsilon_{t}^{q} \sim \text { i.i.d.N }\left(0, \sigma_{q}^{2}\right),
$$

where $q^{*}$ is the deterministic steady state value of $q_{t}$. In the following analysis, i.i.d. shocks $\epsilon_{t}^{g}, \epsilon_{t}^{a}$, and $\epsilon_{t}^{q}$ are assumed to be uncorrelated at all leads and lags.

The first-order necessary conditions for the household's problem of maximizing the lifetime utility function (13) subject to the constraints (14)-(20) must be satisfied at any equilibrium of this small open economy. The transversality conditions $\lim _{i \rightarrow \infty} \beta^{i} E_{t}\left\{\lambda_{K, t+i} K_{t+1+i}\right\}=0$ and $\lim _{i \rightarrow \infty} \beta^{i} E_{t}\left\{\lambda_{B, t+i} B_{t+1+i}\right\}=0$ must be satisfied at any equilibrium for sufficiency, where $\lambda_{K, t}$ and $\lambda_{B, t}$ are shadow prices corresponding to the law of motion of capital (16) and the budget constraint (14), respectively. The first-order necessary conditions and transversality conditions then establish the unique equilibrium path of the small open economy.

\subsection{Bayesian estimation of the model}

This paper estimates the SOE-RBC model introduced above (hereafter, the Benchmark model) to distinguish between the roles habit formation and the persistence of the world real interest rate play in current account fluctuations. To do so, I employ a Bayesian posterior simulation method applied by Schorfheide (2000), Chang et al.(2002), and Bouakez and Kano (2006) to empirical investigation of several DSGE models. Let $\theta$ denote the vector of the structural parameters of the

\footnotetext{
${ }^{20}$ The endogenous risk premium in equation (17) excludes an explosive/unit root path of international bonds in the linearized solution of the equilibrium. Moreover, it solves the well-known problem in SOE-RBC models that the deterministic steady state depends on the initial condition.

${ }^{21}$ For example, consider the government budget that $G_{t}$ is financed by lump-sum tax $T_{t}$ satisfying $T_{t}=g_{t} Y_{t}$.
} 
Benchmark model. The estimation procedure then consists of the following steps. I take the loglinear approximation of the stochastically detrended first-order necessary conditions of the model around the deterministic steady state, and solve the resulting linear rational expectations model to derive the corresponding state space representation exploiting Sim's (2002) algorithm. The state-space representation of the model, together with the data $\mathbf{Y}$, produces the likelihood function $p(\mathbf{Y} \mid \theta)$ through recursively using a Kalman filter. The likelihood function is combined with prior distributions of the structural parameters, $p(\theta)$, to obtain posterior distributions $p(\theta \mid \mathbf{Y})$. Bayesian estimates (i.e., the posterior means of the structural parameters) are computed with 50,000 draws from the posterior distributions centered around the corresponding modal values with a randomwalk Metropolis-Hastings algorithm.

This paper constructs the prior distributions of the structural parameters of the model, $p(\theta)$, consistently with those assumed by NR, except for the habit parameter $h$ and the $\operatorname{AR}(1)$ coefficient of the world real interest rate process, $\rho_{r}$. As the prior distributions of these two structural parameters, I use the identical Beta distribution with the mean of 0.710 and the standard deviation of 0.176 . Choosing the identical prior distributions of the two critical parameters, I intend a fair comparison between habit formation and the persistence of the world real interest rate shock as significant generators of current account fluctuations. Table 1 summarizes the prior distributions of the structural parameters of the Benchmark model.

The first and second columns of Tables 2(a) and (b), which are denoted by "Benchmark", report the posterior means and standard deviations of the structural parameters of the Benchmark model based on the data of Canada and the United Kingdom, respectively (I will explain the other columns in the two tables below). The most striking observation in these columns is that on the one hand, the posterior means of the habit parameter are equal to 0.084 and 0.073 for Canada and the United Kingdom, respectively. Given the restrictions provided by the Benchmark model, the data of the two economies, therefore, update the relatively large prior mean value of the habit parameter of 0.701 to these tiny values. On the other hand, the same columns of the tables report that the posterior means of the $\mathrm{AR}(1)$ coefficient of the world real interest rate are 0.976 and 0.861 for Canada and the United Kingdom. The data of the two economies, hence, update the identical prior mean value of the $\mathrm{AR}(1)$ coefficient of the world real interest rate of 0.701 to much larger values significantly different from zero. In summary, the data of the two economies sharply dampen the significance of habit formation and support the importance of the persistence of the world real interest rate.

To clarify this paper's inference on the role of habit formation in the data of the two economies, I repeat the above Bayesian posterior simulation exercise with three different specifications of the Benchmark model. In the first specification (hereafter, the Habit model), I assume that the world real interest rate is purely transitory and eliminate the $\operatorname{AR}(1)$ coefficient $\rho_{r}$ from the Benchmark model to check whether the habit parameter $h$ is significantly identified without the persistence of the world real interest rate. The second specification (hereafter, the WRI model) is equivalent to the SOR-RBC model of NR, i.e., the Benchmark model without habit formation. Finally, the fourth specification (hereafter, the no Habit/WRI model) is constructed by dropping 
both of habit formation and the $\mathrm{AR}(1)$ coefficient of the world real interest rate from the Benchmark model. The role of the fourth specification is to figure out what gains these two mechanisms bring to the canonical SOE-RBC model.

The third and fourth columns of Tables 2(a) and (b) report three important observations about the Habit model. First, the habit parameter is tightly estimated in the two economies, as expected. Together with the inference form the Benchmark model, this result strongly supports this paper's conjecture that in the habit-forming PVM, the habit parameter might be identified as a substitute of the persistent world real interest rate. The second important observation from the Habit model is that without the persistence of the world real interest rate, habit formation leads to unreasonably high estimates of the unconditional mean of the world real interest rate, $q^{*}$, in the two countries. Conditional on the Habit model, the Canadian data update the prior mean of $q^{*}$ of 2.830 percent at annual rate (equivalent to 0.700 percent at quarterly rate) to 7.400 percent at annual rate, and the data of the United Kingdom update the identical prior mean of $q^{*}$ to 6.560 percent at annual rate 22 The third critical observation is that the Habit model is defeated by the Benchmark model with respect to the overall statistical fit. To measure the overall statistical fit of a model, I calculate the marginal likelihood of the model 23 The marginal likelihood is the probability of the data $\mathbf{Y}$ conditional on the underlaying model. In general, the higher the marginal likelihood is, the better the underlying model's fit to the data is. The last rows of the columns denoted "Benchmark" and "Habit" in Tables 2(a) and (b) depict their marginal likelihoods for Canada and the United Kingdom, respectively. In each economy, the Benchmark model yields a higher marginal likelihood than the Habit model does (1130.253 versus 1013.425 in Canada and 999.229 versus 828.568 in the United Kingdom). This is strong evidence that replacing the persistence of the world real interest rate to habit formation makes the overall fit of the Benchmark model to the data worse significantly.

Similarly, the sixth and seventh columns of Tables 2(a) and (b) report the results of the posterior simulation with the WRI model. As expected, the posterior distributions of the structural parameters implied by this specification are almost identical of those of the Benchmark model. The significant difference between the Benchmark and WRI models is found in their marginal likelihoods: the WRI model yields a much higher marginal likelihood than the Benchmark model does (1144.222 versus 1130.253 in Canada and 1011.292 versus 999.229 in the United Kingdom). This result leads to an inference that even a small degree of habit formation makes the overall statistical fit of the Benchmark model worse than the case without habit formation. The WRI model has a better fit to the data than the Benchmark model does because of its parsimony.

Finally, the last two columns of Tables $2(\mathrm{a})$ and (b) show the results of the no-Habit/WRI model that are endowed with none of habit formation and the $\operatorname{AR}(1)$ coefficient of the world real interest rate. As the corresponding marginal likelihoods imply, this specification yields the worst fit

\footnotetext{
${ }^{22}$ This posterior inference might recall the observation by Otrok et al. (2002) that given the postwar U.S. consumption process, a Lucas-type consumption-based asset pricing model incorporated with habit formation yields a counterfactually large average risk-free rate by making the representative consumer more averse to high-frequency fluctuations in consumption.

${ }^{23}$ This paper estimates marginal likelihoods exploiting Geweke's (1999) modified harmonic mean estimator.
} 
to the data of the two economies. Comparing the marginal likelihood of this specification (799.112 in Canada and 668.407 in the United Kingdom) with that of the WRI model (1144.222 in Canada and 1011.292 in the United Kingdom), I observe that the persistence of the world real interest rate improves the fit of the canonical SOE-RBC model by 43.2 percent in Canada and 53.3 percent in the United Kingdom. From this observation, this paper infers that the persistence of the world real interest rate plays a crucial role in the joint dynamics of the current account-net output ratio, the consumption-output ratio, and the net output growth rate in the two proto-type small open economies. Given the persistent world real interest rate, there is unlikely to be any room for habit formation to play in the data crucially.

\subsection{Can the models replicate Gruber's moments?}

Given the posterior inference of the dominate role of the persistent world real interest rate in the two country's data over habit formation, a natural question is: can the estimated SOE-RBC models replicate the GMM statistics of the habit-forming PVM which are displayed in Figures 1 and 2? To answer this question, I conduct Bayesian Monte Carlo simulation exercises following DeJong et al.(2002), Geweke (2007), and NR in this section. The results of the Bayesian moment-matching exercises in this subsection are consistent with those from the Bayesian posterior simulation in the last subsection: the Benchmark model as well as the WRI model replicates all the empirical moments observed in Figures 1 and 2, while the Habit model does not.

To implement the moment matching exercises, I construct the theoretical distributions of the moments of the habit-forming PVM, $\mathbf{m}_{h}, \mathbf{m}_{J}, \mathbf{m}_{\mathcal{H}}$, and $\left\{\mathbf{m}_{c a, t}\right\}_{t=1}^{T}$, which are implied by the Benchmark and Habit models, respectively 24 For each SOE-RBC model, I first randomly draw 5,000 sets of the structural parameters of the model, $\theta$, from the posterior distribution $p(\theta \mid \mathbf{Y})$ that is simulated with either of the Canadian or the U.K. data in section 4.2. Conditional on each posterior draw of the structural parameters $\theta$, I simulate 100 synthetic time series of vector $\mathbf{X}$ with the corresponding model, which then yield 100 repetitions of statistics $\hat{h}, \hat{\mathcal{J}}, \hat{\mathcal{H}}$, and $\left\{c a_{t}^{f}\right\}_{t=1}^{T}$, respectively 25 Taking the averages over the 100 repetitions of these statistics constructs a set of synthetic population means $\mathbf{m}_{h}, \mathbf{m}_{J}, \mathbf{m}_{\mathcal{H}}$, and $\left\{\mathbf{m}_{c a, t}\right\}_{t=1}^{T}$. I repeat this process for the 5,000 posterior sets of the structural parameters to construct the theoretical distributions of the population means implied by the underlying model.

Figure 3(a) plots the nonparametrically smoothed theoretical densities of population means $\mathbf{m}_{h}$ and $\mathbf{m}_{J}$, i.e., the habit parameter of the habit-forming PVM and the J statistic for the overidentifying restrictions, implied by the Benchmark and Habit models for Canada as the green solid lines. Each window in the figure depicts the corresponding empirical distribution as the blue dotted line. As the upper-left window shows, the Benchmark model implies the theoretical distribution of $\mathbf{m}_{h}$ that significantly overlaps over its empirical counterpart, even though the mean of the theoretical distribution, 0.492 , is smaller than that of the empirical distribution, 0.701 . To gauge the

\footnotetext{
${ }^{24}$ The WRI model yields the almost identical results with the Benchmark model. The results of the WRI model are available upon request to the author.

${ }^{25}$ Simulation of artificial series $\mathbf{X}$ is based on the state-space representation of the model.
} 
degree of overlapping more formally, I also calculate the confidence interval criterion (CIC) statistic proposed by DeJong et al.(2002). The CIC with $1-\omega$ percent confidence level counts the fraction of a theoretical distribution that exists within an interval from the lower $0.5 \omega$ quantile to the upper $1-0.5 \omega$ quantile of the corresponding empirical distribution. By construction, the closer the CIC is to $1 /(1-\omega)$, the better the fit of the underlying SOE-RBC model to the empirical moment is. As reported in the upper-left window of Figure 3(a), the CIC of the Benchmark model with 95 percent confidence level (i.e., $\omega=0.05$ ) is 1.000, which is strong evidence that the Benchmark model replicates the empirical moment $\mathbf{m}_{h}$ quite successfully for Canada. The upper-right window displays the theoretical distribution of population mean $\mathbf{m}_{h}$ implied by the Habit model. Notice that the theoretical distribution is tightly concentrated on the negative region with mean -0.109 and standard deviation 0.087. This means that the Habit model fails to match the empirical moment $\mathbf{m}_{h}$. The corresponding CIC value of almost zero formally conveys the failure of the Habit model with respect to this statistical dimension in the Canadian data. As uncovered in the second row of Figure 3(a), neither the Benchmark model nor the Habit model replicates the empirical distributions of population mean $\mathbf{m}_{J}$, i.e., the $\mathrm{J}$ statistic for the overidentifying restrictions implied by the habit-forming PVM, in the Canadian sample. The two SOE-RBC models imply the theoretical distributions of $\mathbf{m}_{J}$ far from the empirical counterpart visually as well as statistically with the CIC values of almost zero.

A clear difference between the Benchmark and Habit models is observed in terms of the habit-forming PVM's forecast of the current account-net output ratio, $\left\{\mathbf{m}_{c a, t}\right\}_{t=1}^{T}$. In each window of Figure 3(b), the actual current account-net output ratio is represented by the blue solid line, the lower and upper bounds of the 90 percent theoretical pointwise credible intervals the green dashed lines, and the lower and upper bounds of the 90 percent empirical pointwise credible intervals the blue dotted lines, respectively. The left window reveals that the Benchmark model does a fairly good job in generating the habit-forming PVM's current account forecast consistent with the actual Canadian current account-net output ratio. In all the sample period, the 90 percent theoretical credible intervals include the actual current account-net output and overlap tightly with the 90 percent empirical credible intervals. As shown in the right window of the figure, the Habit model, however, generates the habit-forming PVM's forecast of the current account-net output ratio that is counterfactually volatile. Indeed, the 90 percent theoretical credible intervals implied by the Habit model fail to contain the actual Canadian current account-net output at almost all sample periods.

The source of the observed excess volatility of the current account-net output forecast implied by the Habit model is clearly found in Table 3 that summarizes the empirical and theoretical distributions of cross-equation restrictions $\mathbf{m}_{\mathcal{H}}$. The rows of Table 3(a) correspond to the six elements of vector $\mathcal{H}$. The first column reports the empirical posterior means of the elements of $\mathbf{m}_{\mathcal{H}}$, while the second and third columns of the table describe the theoretical means of the elements of $\mathbf{m}_{\mathcal{H}}$ implied by the Benchmark and Habit models, respectively. The numbers in the third and fifth columns are the standardized difference in means (SDM) statistics calculated for the corresponding means of the element of $\mathbf{m}_{\mathcal{H}}$. An SDM is a t-ratio like statistic constructed by taking the difference between the means of theoretical and empirical distributions and dividing the result 
by the empirical standard deviation. The closer the SDM is to zero, the better the fit of the model with respect to the statistical dimension of interest is. The table uncovers that the major failure of the Habit model in the Canadian data is in its implication for the second element of $\mathbf{m}_{\mathcal{H}}$ : the Habit model implies the counterfactually large (in the absolute value) theoretical posterior mean of the second element of $\mathbf{m}_{\mathcal{H}}$ of -1.807 accompanied with the large SDM of -12.119. By construction of the cross-equation restrictions $\mathcal{H}$ of the habit-forming PVM (11), this observation means that the Habit model overemphasizes the role the current consumption-output ratio plays in fluctuations of the current account-net output ratio.

From Figures 4(a) and (b) and Table 3(b), I can draw the surprisingly similar inferences of the Benchmark and Habit models with respect to the moments of the habit-forming PVM even with the data of the United Kingdom. Firstly, as displayed in the first row of Figure 4(a), the Benchmark model replicates the empirical posterior distribution of $\mathbf{m}_{h}$ quite successfully with the high CIC of 1.030, while the Habit model implies the theoretical distribution of $\mathbf{m}_{h}$ far away from the empirical counterpart with the negative mean of -0.200 and the CIC of almost zero. Secondly, the second row of Figure 4(b) exhibits that the Benchmark model does a good job in matching the U.K. moment $\mathbf{m}_{J}$ with the relatively high CIC of 0.370. Yet, the Habit model fails to explain this moment, as the small CIC of 0.010 shows formally. As the third inference obtained in Figure 4(b), the Habit model implies the counterfactually volatile current account-net output forecast based on the habit-forming PVM's restrictions compared to the actual current account-net output time series of the United Kingdom, while the Benchmark model yields the forecast of the current account-net output ratio tracking the actual one very precisely. Finally, as the fourth inference, this volatile forecast of the current account-net output ratio implied by the Habit model stems from the excess sensitivity of the fluctuations of the current account-net output ratio to contemporaneous variations in the current consumption-output ratio. This inference is clearly drawn from Table 3(b) in which similarly to the Canadian case, the posterior mean of the theoretical distribution of the second element of vector $\mathbf{m}_{\mathcal{H}}$ implied by the Habit model is huge in the absolute value (-3.174) with the large SDM (-7.410).

\section{Conclusion}

In a recent paper, Gruber extends the standard PVM of the current account with habit formation in consumption, and claims that this feature improves the ability of the PVM to track actual current movements of selected developed economies.

In this paper, however, I argue that the habit-forming PVM is observationally equivalent to the canonical PVM augmented with persistent transitory consumption shocks, which are well represented by persistent world real interest rate shocks. This finding implies that the test statistics

Gruber proposes to estimate and evaluate the habit-forming PVM are not informative for identifying the role of habit formation in current account dynamics: given the process of the net output growth rate, the alternative PVM predicts the identical time-series of the current account measure as does 
the habit-forming PVM. Therefore, the good forecasting ability of the habit-forming PVM could be interpreted as the results of persistent world real interest rates shocks, instead of habit formation.

This identification problem is attributed to the partial equilibrium approach of the habitforming PVM. The habit-forming PVM imposes no restrictions on the stochastic dynamics of net output growth. In this paper, therefore, I identify the role of habit formation in current account dynamics by exploiting the restrictions SOE-RBC models impose on net output growth as well as the current account. Conducting Bayesian exercises with the SOE-RBC models with and without habit formation, I find no support for a significant role habit formation plays in the current account fluctuations in post-Bretton Woods periods of Canada and the United Kingdom. In fact, adding habit formation to the canonical SOE-RBC model of NR makes the model's fit to actual data much worse. Therefore, the results of this paper cast serious doubt whether habit formation could be a prime suspect for generating current account fluctuations in the two small open economies. 


\section{Appendices}

\section{A.1. Deriving vector $\mathcal{H}$}

Taking one-period lead of the habit-forming PVM (8) and the conditional expectation of the result yields

$$
E_{t} c a_{t+1}^{*}=h c a_{t}^{*}+h \kappa E_{t} \Delta n y_{t+1}^{*}-(1-h \kappa) \sum_{i=1}^{\infty} \kappa^{i} E_{t} \Delta n y_{t+i+1}^{*} .
$$

Exploiting the first-order representation of the $\operatorname{VAR}(\mathrm{p})$ and unit vectors $\mathbf{e}_{i}$ and $\mathbf{e}_{j}$ rewrite equation (A.1) as

$$
\mathbf{e}_{j} \mathcal{A} Y_{t}=h c a_{t}^{*}+h \kappa \mathbf{e}_{i} \mathcal{A} Y_{t}-(1-h \kappa) \mathbf{e}_{i} \mathcal{A}^{2}(I-\kappa \mathcal{A})^{-1} Y_{t} .
$$

Equation (A.2) implies

$$
\begin{aligned}
c a_{t}^{*} & =(1-h) c a_{t}^{*}+\mathbf{e}_{j} \mathcal{A} Y_{t}-h \kappa \mathbf{e}_{i} \mathcal{A} Y_{t}+(1-h \kappa) \mathbf{e}_{i} \kappa \mathcal{A}^{2}(I-\kappa \mathcal{A})^{-1} Y_{t} \\
& =(1-h) \mathbf{e}_{j} Y_{t}+\left\{\left[\mathbf{e}_{j}-h \kappa \mathbf{e}_{i}+(1-h \kappa) \mathbf{e}_{i} \kappa \mathcal{A}(I-\kappa \mathcal{A})^{-1}\right] \mathcal{A}\right\} Y_{t} \\
& =\mathcal{H}(h, \mathcal{A} ; \kappa) Y_{t} . \\
& \equiv c a_{t}^{f}
\end{aligned}
$$

Notice that under the null of the habit-forming PVM, $c a_{t}^{f}=c a_{t}^{*}$ and $\mathcal{H}(h, \mathcal{A} ; \kappa)=\mathbf{e}_{j}$. Moreover, observe that if the PVM with a transitory consumption component, equation (10), is the case, $\mathcal{H}(\rho, \mathcal{A} ; \kappa)=\mathbf{e}_{j}$. Therefore, the two PVMs impose the same cross-equation restrictions on the unrestricted VAR.

\section{A.2. Deriving the stochastic process $d_{t}=h d_{t-1}+\epsilon_{t}-\kappa^{-1} \epsilon_{t-1}+e_{t}$}

Substituting the habit-forming PVM (8) into the definition of $d_{t}$ yields

$$
\begin{aligned}
d_{t} & \equiv c a_{t}^{*}-\Delta n y_{t}^{*}-\kappa^{-1} c a_{t-1}^{*} \\
& =h c a_{t-1}^{*}+h \kappa \Delta n y_{t}^{*}-(1-h \kappa) \sum_{i=1}^{\infty} \kappa^{i} E_{t} \Delta n y_{t+i}^{*}+\epsilon_{t}-\Delta n y_{t}^{*}-\kappa^{-1} c a_{t-1}^{*} \\
& =-\left(\kappa^{-1}-h\right) c a_{t-1}^{*}-(1-h \kappa) \sum_{i=0}^{\infty} \kappa^{i} E_{t} \Delta n y_{t+i}^{*}+\epsilon_{t} \\
& =h d_{t-1}-h d_{t-1}-\left(\kappa^{-1}-h\right) c a_{t-1}^{*}-(1-h \kappa) \sum_{i=0}^{\infty} \kappa^{i} E_{t} \Delta n y_{t+i}^{*}+\epsilon_{t} .
\end{aligned}
$$

Substituting the definition of $d_{t-1}$ into the second term of the RHS of equation.(A.4) and using the habitforming PVM (8) to eliminate the resulting term $c a_{t-1}^{*}$ further rewrites equation. (A.4) as

$$
\begin{aligned}
d_{t} & =h d_{t-1}-\kappa^{-1} c a_{t-1}^{*}+h \Delta n y_{t-1}^{*}+h \kappa^{-1} c a_{t-2}^{*}-(1-h \kappa) \sum_{i=0}^{\infty} \kappa^{i} E_{t} \Delta n y_{t+i}^{*}+\epsilon_{t} \\
& =h d_{t-1}+\epsilon_{t}-\kappa^{-1} \epsilon_{t-1}-(1-h \kappa) \sum_{i=0}^{\infty} \kappa^{i}\left(E_{t}-E_{t-1}\right) \Delta n y_{t+i}^{*} \\
& =h d_{t-1}+\epsilon_{t}-\kappa^{-1} \epsilon_{t-1}+e_{t}
\end{aligned}
$$


Notice that the last term of the above equation $e_{t}=-(1-h \kappa) \sum_{i=0}^{\infty} \kappa^{i}\left(E_{t}-E_{t-1}\right) \Delta n y_{t+i}^{*}$ is the revision of the expectation with respect to the current and future net output growth rates between periods $t-1$ and $t$. Therefore, $e_{t}$ should be orthogonal to the information set at period $t-1$.

\section{A.3. Data description and construction}

All Canadian data are distributed by Statistics Canada CANSIM II (http://www.statcan.ca/). The current account series $C A_{t}$ are constructed by net foreign interest payment plus net export. As net foreign interest payment, this paper uses Net Investment Income from Non Residents(v499687). The net export series are obtained by Exports of Goods and Services (v1992249) minus Imports of Goods and Services (v1992253). The net output series $N Y_{t}$ are given by GDP(v1992259) minus Business Gross Fixed Capital Formation(v1992238) minus Business Investment in Inventories(v1992245) minus Government Current Expenditure on Goods and Services(v1992235) minus Government Gross Fixed Capital Formation(v1992236) minus Government Investment in Inventories(v1992237) minus Personal Expenditure on Durable Goods(v1992230) minus Personal Expenditure on Semi-Durable Goods(v1992231). The series of the log of the consumptionoutput ratio $c_{t}-y_{t}$ are constructed by dividing the sum of Personal Expenditure on Non-Durable(v1992232) and Personal Expenditure on Services (v1992233) by GDP and taking the log of the result. All the series are seasonally adjusted at annual rates, divided by Estimates of Population(v1), and at 1997 constant prices except for Net Investment Income from Non Residents, which is converted to real series with the GDP deflator.

U.K. data are taken from the U.K. National Statistics database (http://www.statistics.gov.uk/). The current-account series $C A_{t}$ is constructed as net foreign interest payments plus net exports. Net foreign interest payments are measured by Net income from abroad (CAES). Net exports are measured by Total Export (IKBH) minus Total Import (IKBI). The net-output series, $N Y_{t}$, is constructed as GDP (YBHA) minus Total Gross Fixed Capital Formation (NPQS) minus Changes in Inventories (CAEX) minus Durable Goods (UTIB) minus Semidurable Goods (UTIR) minus General Government Final Consumption Expenditure (NMRP). The series of the log of the consumption-output ratio $c_{t}-y_{t}$ are constructed by dividing the sum of Non-durable goods(UTIJ) and Services (UTIN) by GDP and taking the log of the result. All series are seasonally adjusted at annual rates, converted to real terms using the GDP deflator, and divided by Total Population (GBRPOP). The latter series is taken from the OECD database. 


\section{References}

Abel, A.B., 1990, "Asset prices under habit formation and catching up with the Jones", American Economic Review 80, 38 - 42.

Bergin, P. R., Sheffrin, S. M.,2000, "Interest rates, exchange rates and present value models of the current account". Economic Journal, 110:535 - 558.

Bouakez, H., Kano, T., 2006, "Learning-by-doing or habit formation", Review of Economic Dynamics, 9: 508-524.

Bouakez, H., Kano, T., 2008, "Terms of trade and current account fluctuations: the HarbergerLaursen-Metzler effect revisited", Journal of Macroeconomics, 30, 261-281.

Blankenau, W., Kose, M. A., Yi, K.-M. , 2001, "Can world real interest rates explain business cycles in a small open economy?", Journal of Economic Dynamics and Control 25, 867 - 889.

Bussière, M., Fratzscher, M., Müller, G.J., 2004, "Current account dynamics in OECD and EU accending countries - an intertemporal approach", ECB working paper No.311.

Campbell, J. Y., Mankiw, N. G., 1989, "Consumption, income, and interest rates: reinterpreting the time series evidence", in O. J. Blanchard and S. Fischer eds. NBER macroeconomics annual 1989, MIT Press, Cambridge, MA.

Campbell, J. Y., Cochrane, J. H., 1999, "By force of habit: a consumption-based explanation of aggregate stock market behavior", Journal of Political Economy 107, 205 - 251.

Chang, Y., Gomes, J.F., Schorfheide, F., 2002, "Learning-by-doing as a propagation mechanism", American Economic Review 92, 1498 - 1520.

Davidson, R., MacKinnon, J.G., 1993, Estimatation and Inference in Econometrics, Oxford University Press, New York.

DeJong, D.N., Ingram, B.F., Whiteman, C.H., 1996, "A Bayesian approach to calibration", Journal of Business and Economic Statistics 14, 1-10.

Dynan, K.B., 2000, "Habit formation in comsumer preferences: evidence from panel data", American Economic Review 90, 391 - 406.

Geweke, J.F., 1999, "Using Simulation Methods for Bayesian Econometric Models: Inference, Development, and Communication." Econometric Reviews 18, 1-126.

Geweke, J., 2007, "Models, computational experiments and reality", Department of Economics and Statistics, University of Iowa, mimeo.

Ghosh, A. R., 1995, "International capital mobility amongst the major industrialised countries: too little or too much?", The Economic Journal 105, 107 - 128. 
Glick, R., Rogoff, K., 1995, "Global versus country-specific productivity shocks and the current account", Journal of Monetary Economics 35, 159 - 192.

Gruber, J. W., 2004, "A present value test of habits and the current account", Journal of Monetary Economics 51, 1495 - 1507.

Hansen, L. P., 1982, "Large sample properties of generalized method of moments estimators", Econometrica 50, 1029 - 1054.

İşcan, T. B., 2000, "The terms of trade, productivity growth, and the current account", Journal of Monetary Economics 45, 587 - 611.

Kano, T., 2008, "A structural VAR approach to the intertemporal model of the current account", Journal of International Money and Finance 27, 757 - 779.

King, R. G., Plosser, C. I., Rebelo, S. T., 1988, "Production, growth, and business cycles II: new directions", Journal of Monetary Economics 21, 309 - 341.

Nason, J. M., Rogers, J. H., 2002, "Investment and the current account in the short run and long run", Journal of Money, Credit, and Banking 34, 967 - 986.

Nason, J.M., Rogers, J.H., 2006, "The present-value model of the current account has been rejected: round up the usual suspect", Journal of International Economics, 68, 159 - 187.

Newey, W., West, K.D., 1987, "A simple, positive semi-definite, heteroskedasticity and autocorrelation consistent covariance matrix", Econometrica, 55, $703-708$.

Obstfeld, M., Rogoff, K., 1995, "The intertemporal approach to the current account", in G. M. Grossman and K. Rogoff eds. Handbook of International Economics, vol.3, North Holland Publishing Co., New York.

Otto, G., 1992, "Testing a present-value model of the current account: Evidence from US and Canadian time series", Journal of International Money and Finance 11, 414 - 430.

Otrok, C., Ravikumar, B., Whiteman, C.H., 2002, "Habit foramtion: a resolution of the equity premium puzzle?", Journal of Monetary Economics 49, 1261 - 1288.

Schmitt-Grohé, S., Uribe, M., 2003, "Closing small open economy models", Journal of International Economics 61, 163 - 185.

Sheffrin, S. M., Woo, W. T., 1990, "Present value tests of an intertemporal model of the current account", Journal of International Economics 29, 237 - 253.

Silverman, B.W., 1986, Density Estimation for Statistics and Data Analysis, Chapman and Hall, London, England.

Schorfheide, F., 2000, "Loss function-based evaluation of DSGE models", Journal of Applied Econometrics $15,645-670$. 
Sims, C.A., 2002, "Solving linear rational expectations models", Computational Economics 20, $1-20$. 
Table 1: Prior distributions of the Benchmark model

\begin{tabular}{lcccc}
\hline \hline Parameters & Distribution & Mean & S.D. & $95 \%$ interval \\
\hline$h$ & Beta & 0.710 & 0.176 & {$[0.375,0.952]$} \\
$\beta$ & Beta & 0.990 & 0.001 & {$[0.988,0.992]$} \\
$\phi$ & Beta & 0.372 & 0.020 & {$[0.339,0.405]$} \\
$\psi$ & Beta & 0.350 & 0.020 & {$[0.317,0.383]$} \\
$\eta$ & Beta & 0.007 & 0.002 & {$[0.004,0.011]$} \\
$\varphi$ & Beta & 0.050 & 0.010 & {$[0.034,0.067]$} \\
$\delta$ & Beta & 0.020 & 0.005 & {$[0.013,0.029]$} \\
$g^{*}$ & Beta & 0.232 & 0.020 & {$[0.199,0.265]$} \\
$q^{*}$ & Beta & 0.007 & 0.001 & {$[0.005,0.008]$} \\
$\rho_{q}$ & Beta & 0.710 & 0.176 & {$[0.375,0.952]$} \\
$\rho_{g}$ & Beta & 0.952 & 0.010 & {$[0.934,0.967]$} \\
$\sigma_{a}$ & Inverse Gamma & 0.012 & 0.010 & {$[0.004,0.028]$} \\
$\sigma_{q}$ & Inverse Gamma & 0.004 & 0.010 & {$[0.000,0.011]$} \\
$\sigma_{g}$ & Inverse Gamma & 0.012 & 0.010 & {$[0.004,0.028]$} \\
\hline \hline
\end{tabular}

Note 1. The prior of the balanced growth rate $\alpha$ is degenerated at the point $\alpha=0.0033$ which is calibrated to the sample mean of the net output growth rate.

Note 2. The 95 percent intervals of $\sigma_{a}, \sigma_{q}$, and $\sigma_{g}$ are constructed based on 10,000 Monte Carlo repetitions. 
Table 2: Posterior distributions of the SOE-RBC parameters

(a) Canada

\begin{tabular}{ccccccccc}
\hline \hline & \multicolumn{2}{c}{ Benchmark } & \multicolumn{2}{c}{ Habit } & \multicolumn{2}{c}{ WRI } & \multicolumn{2}{c}{ no Habit/WRI } \\
Variables & Mean & S.D. & Mean & S.D. & Mean & S.D. & Mean & S.D. \\
\hline$h$ & 0.084 & 0.030 & 0.976 & 0.001 & - & - & - & - \\
$\rho_{q}$ & 0.976 & 0.007 & - & - & 0.983 & 0.006 & - & - \\
\hline$\beta$ & 0.991 & 0.001 & 0.992 & 0.000 & 0.991 & 0.001 & 0.988 & 0.000 \\
$\gamma$ & 0.375 & 0.017 & 0.414 & 0.007 & 0.374 & 0.020 & 0.384 & 0.017 \\
$\psi$ & 0.349 & 0.017 & 0.391 & 0.005 & 0.354 & 0.013 & 0.349 & 0.026 \\
$\eta$ & 0.008 & 0.001 & 0.001 & 0.000 & 0.012 & 0.002 & 0.000 & 0.000 \\
$\varphi$ & 0.086 & 0.007 & 0.115 & 0.001 & 0.082 & 0.004 & 0.151 & 0.000 \\
$\delta$ & 0.015 & 0.002 & 0.018 & 0.002 & 0.018 & 0.003 & 0.002 & 0.001 \\
$g^{*}$ & 0.307 & 0.001 & 0.305 & 0.001 & 0.308 & 0.002 & 0.243 & 0.000 \\
$q^{*}$ & 0.008 & 0.002 & 0.018 & 0.000 & 0.007 & 0.001 & 0.018 & 0.000 \\
$\rho_{g}$ & 0.966 & 0.007 & 0.960 & 0.001 & 0.954 & 0.009 & 0.994 & 0.000 \\
$\sigma_{a}$ & 0.020 & 0.001 & 0.016 & 0.001 & 0.020 & 0.000 & 0.022 & 0.000 \\
$\sigma_{q}$ & 0.001 & 0.000 & 0.002 & 0.000 & 0.001 & 0.000 & 0.002 & 0.000 \\
$\sigma_{g}$ & 0.021 & 0.002 & 0.043 & 0.002 & 0.020 & 0.001 & 0.037 & 0.000 \\
\hline mlike & 1130.253 & 1013.425 & 1144.222 & 799.112 \\
\hline \hline
\end{tabular}

(b) United Kingdom

\begin{tabular}{ccccccccc}
\hline \hline & \multicolumn{3}{c}{ Benchmark } & \multicolumn{2}{c}{ Habit } & \multicolumn{2}{c}{ WRI } & \multicolumn{2}{c}{ no Habit/WRI } \\
Variables & Mean & S.D. & Mean & S.D. & Mean & S.D. & Mean & S.D. \\
\hline$h$ & 0.073 & 0.027 & 0.992 & 0.002 & - & - & - & - \\
$\rho_{q}$ & 0.861 & 0.005 & - & - & 0.832 & 0.006 & - & - \\
\hline$\beta$ & 0.989 & 0.001 & 0.990 & 0.000 & 0.989 & 0.001 & 0.990 & 0.000 \\
$\gamma$ & 0.371 & 0.014 & 0.392 & 0.005 & 0.376 & 0.019 & 0.381 & 0.019 \\
$\psi$ & 0.341 & 0.013 & 0.296 & 0.002 & 0.331 & 0.016 & 0.524 & 0.008 \\
$\eta$ & 0.003 & 0.000 & 0.000 & 0.000 & 0.002 & 0.000 & 0.000 & 0.000 \\
$\varphi$ & 0.096 & 0.004 & 0.083 & 0.001 & 0.076 & 0.006 & 0.158 & 0.000 \\
$\delta$ & 0.017 & 0.002 & 0.008 & 0.001 & 0.014 & 0.003 & 0.012 & 0.001 \\
$g^{*}$ & 0.266 & 0.001 & 0.233 & 0.001 & 0.277 & 0.002 & 0.232 & 0.000 \\
$q^{*}$ & 0.005 & 0.001 & 0.016 & 0.000 & 0.006 & 0.001 & 0.018 & 0.000 \\
$\rho_{g}$ & 0.968 & 0.006 & 0.945 & 0.001 & 0.969 & 0.005 & 0.990 & 0.001 \\
$\sigma_{a}$ & 0.022 & 0.002 & 0.024 & 0.001 & 0.019 & 0.001 & 0.026 & 0.000 \\
$\sigma_{q}$ & 0.001 & 0.000 & 0.010 & 0.001 & 0.001 & 0.000 & 0.002 & 0.000 \\
$\sigma_{g}$ & 0.035 & 0.003 & 0.063 & 0.000 & 0.031 & 0.001 & 0.054 & 0.000 \\
\hline mlike & 999.229 & 828.568 & 1011.292 & 668.407 \\
\hline \hline
\end{tabular}


Table 3: Posterior distributions of $\mathbf{m}_{\mathcal{H}}$

(a) Canada

\begin{tabular}{lccccc}
\hline \hline & Empirical & \multicolumn{2}{c}{ Benchmark } & \multicolumn{2}{c}{ Habit } \\
$\mathcal{H}_{i}$ & Mean & Mean & SDM & Mean & SDM \\
\hline $\mathcal{H}_{1}$ & 0.161 & -0.040 & -2.744 & 0.087 & -1.017 \\
$\mathcal{H}_{2}$ & 0.450 & -0.181 & -3.389 & -1.807 & -12.119 \\
$\mathcal{H}_{3}$ & 0.954 & 1.005 & 0.497 & 1.005 & 0.504 \\
$\mathcal{H}_{4}$ & 0.159 & 0.009 & -3.731 & 0.005 & -2.582 \\
$\mathcal{H}_{5}$ & -0.403 & -0.004 & 4.444 & 0.012 & 4.627 \\
$\mathcal{H}_{6}$ & 0.139 & -0.052 & -3.243 & 0.164 & 0.424 \\
\hline \hline
\end{tabular}

(b) United Kingdom

\begin{tabular}{cccccc}
\hline \hline & Empirical & \multicolumn{2}{c}{ Benchmark } & \multicolumn{2}{c}{ Habit } \\
$\mathcal{H}_{i}$ & Mean & Mean & SDM & Mean & SDM \\
\hline $\mathcal{H}_{1}$ & 0.161 & -0.029 & -1.631 & 0.217 & 1.618 \\
$\mathcal{H}_{2}$ & 0.450 & -0.128 & 0.063 & -3.174 & -7.410 \\
$\mathcal{H}_{3}$ & 0.954 & 1.005 & -0.001 & 1.096 & 0.722 \\
$\mathcal{H}_{4}$ & 0.159 & 0.010 & -1.003 & 0.109 & 1.581 \\
$\mathcal{H}_{5}$ & -0.403 & 0.011 & 0.857 & -0.086 & 0.150 \\
$\mathcal{H}_{6}$ & 0.139 & -0.042 & -2.265 & 0.279 & 2.473 \\
\hline \hline
\end{tabular}


Figure 1: Empirical Distributions of $\mathbf{m}_{h}$ and $\mathbf{m}_{J}$
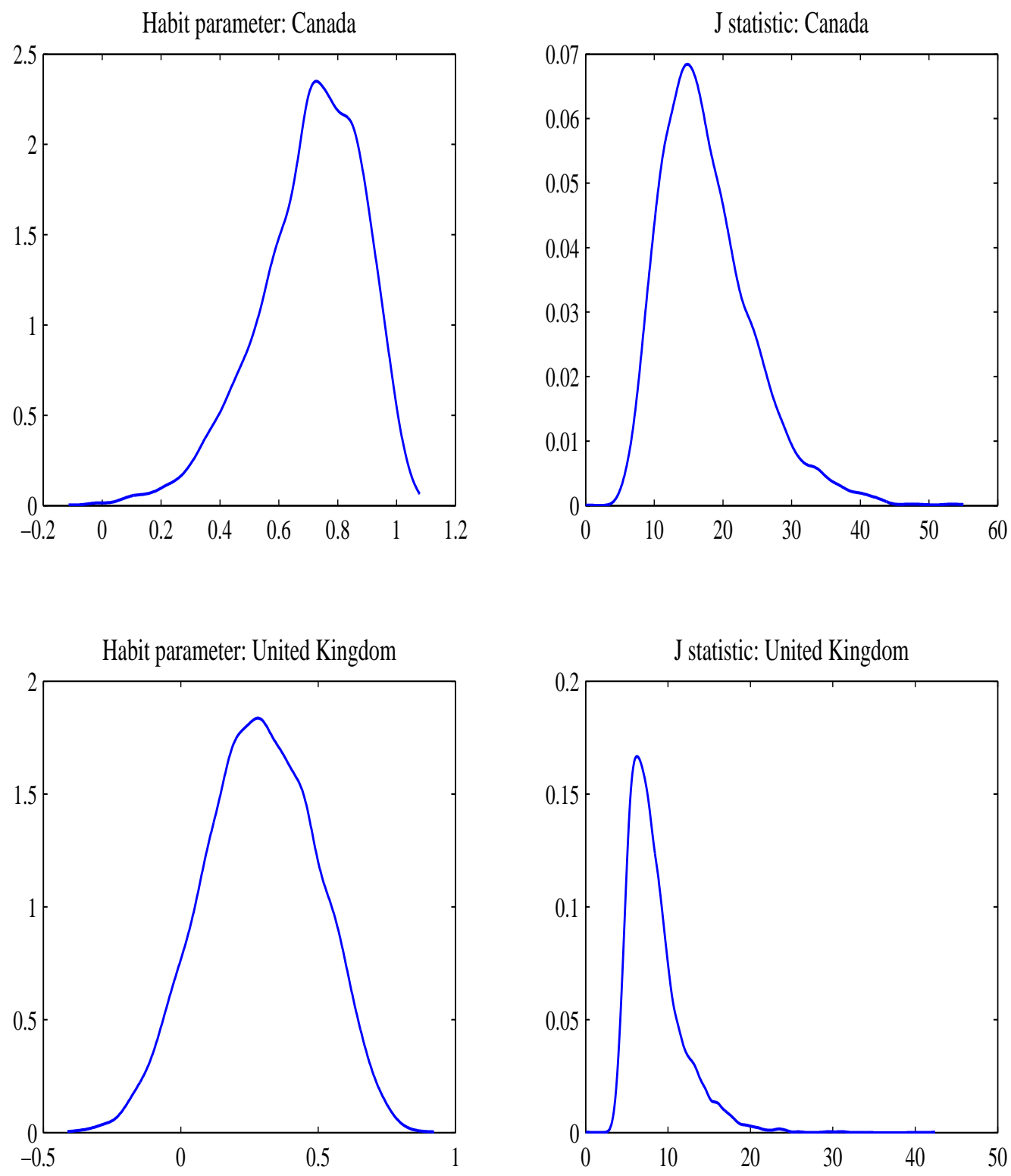
Figure 2: Empirical Distributions of $\mathbf{m}_{c a, t}$
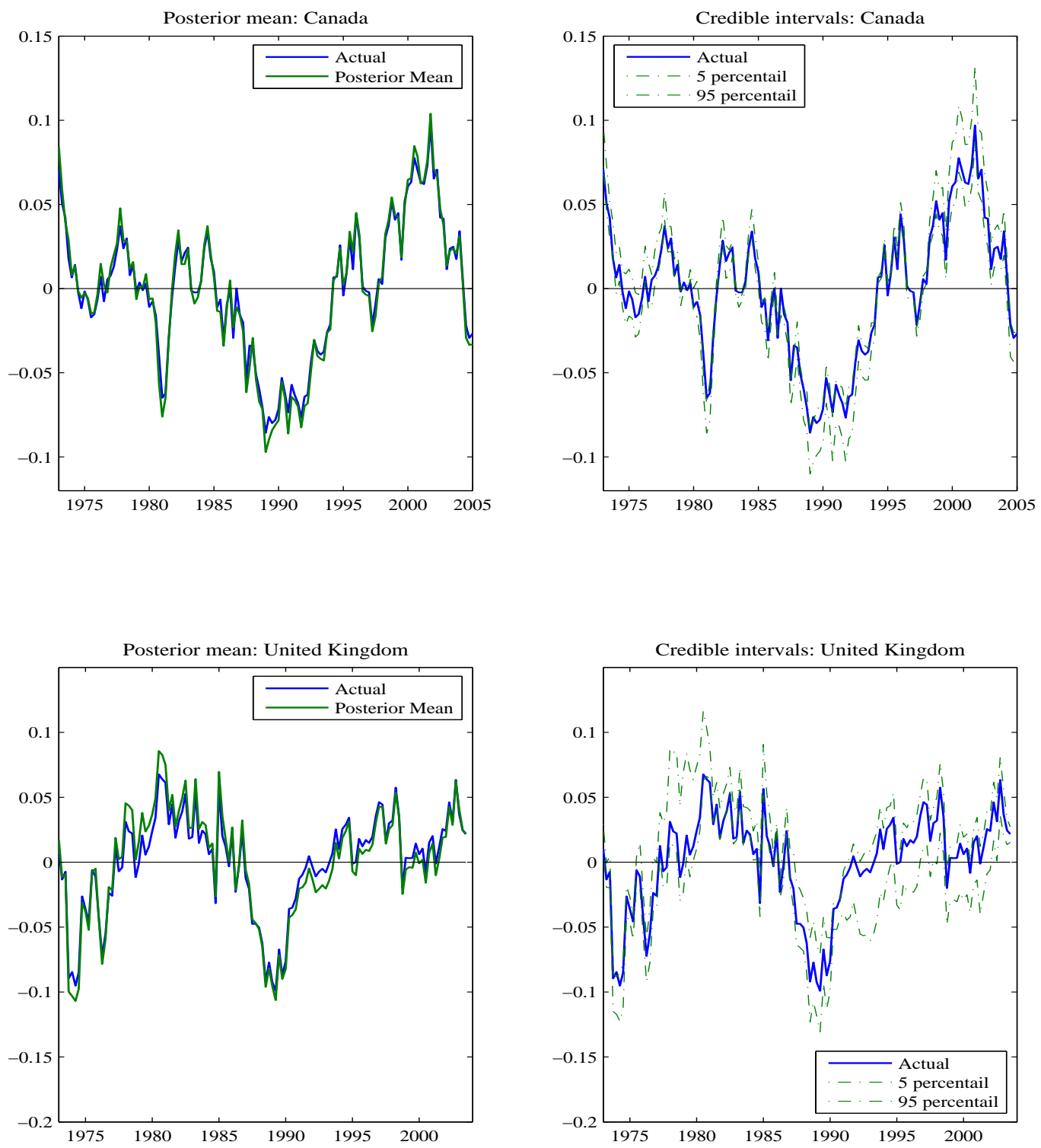
Figure 3(a): Theoretical Distributions of $\mathbf{m}_{h}$ and $\mathbf{m}_{J}$ : Canada
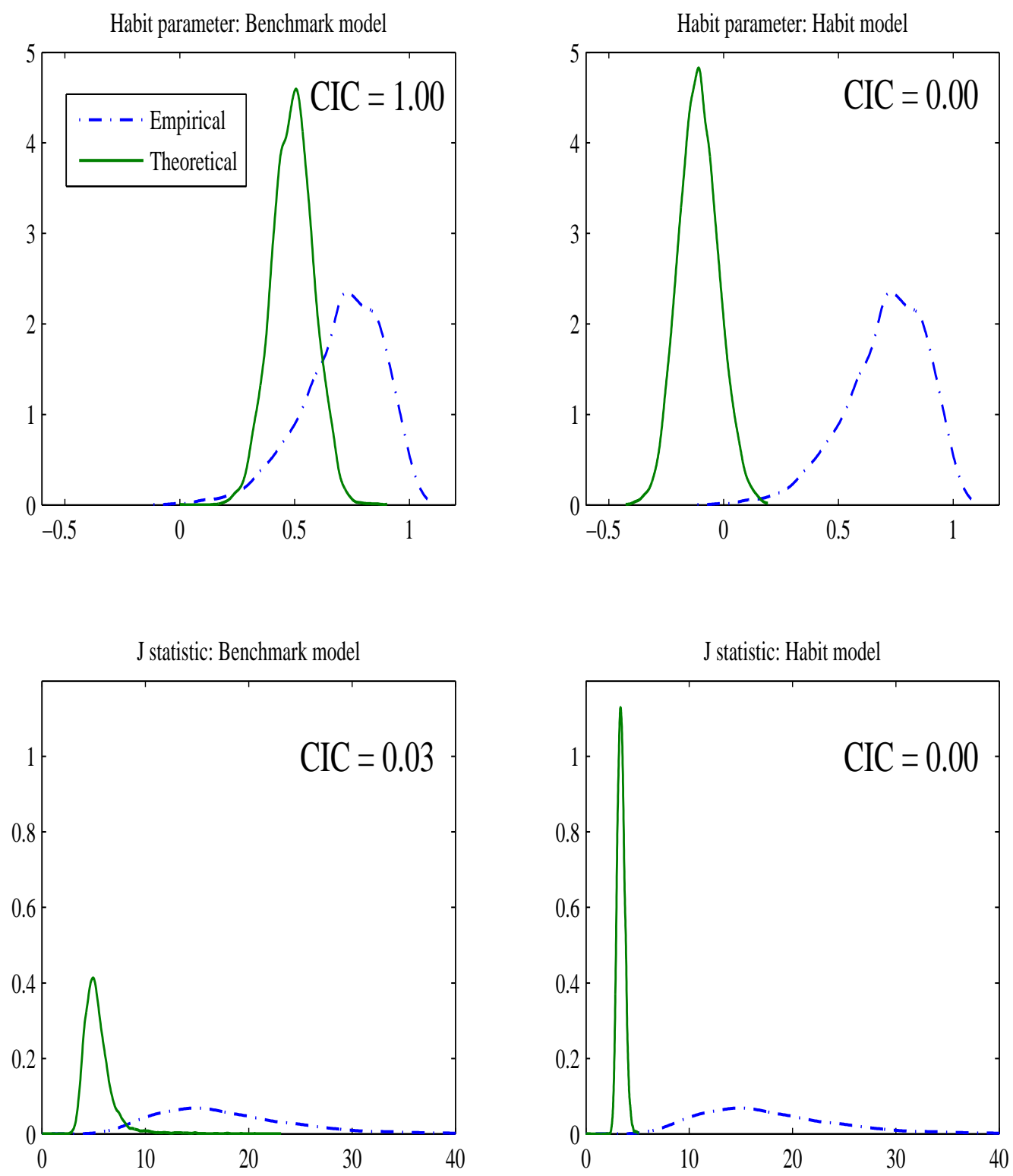
Figure 3(b): Theoretical Distributions of $\mathbf{m}_{c a, t}$ : Canada
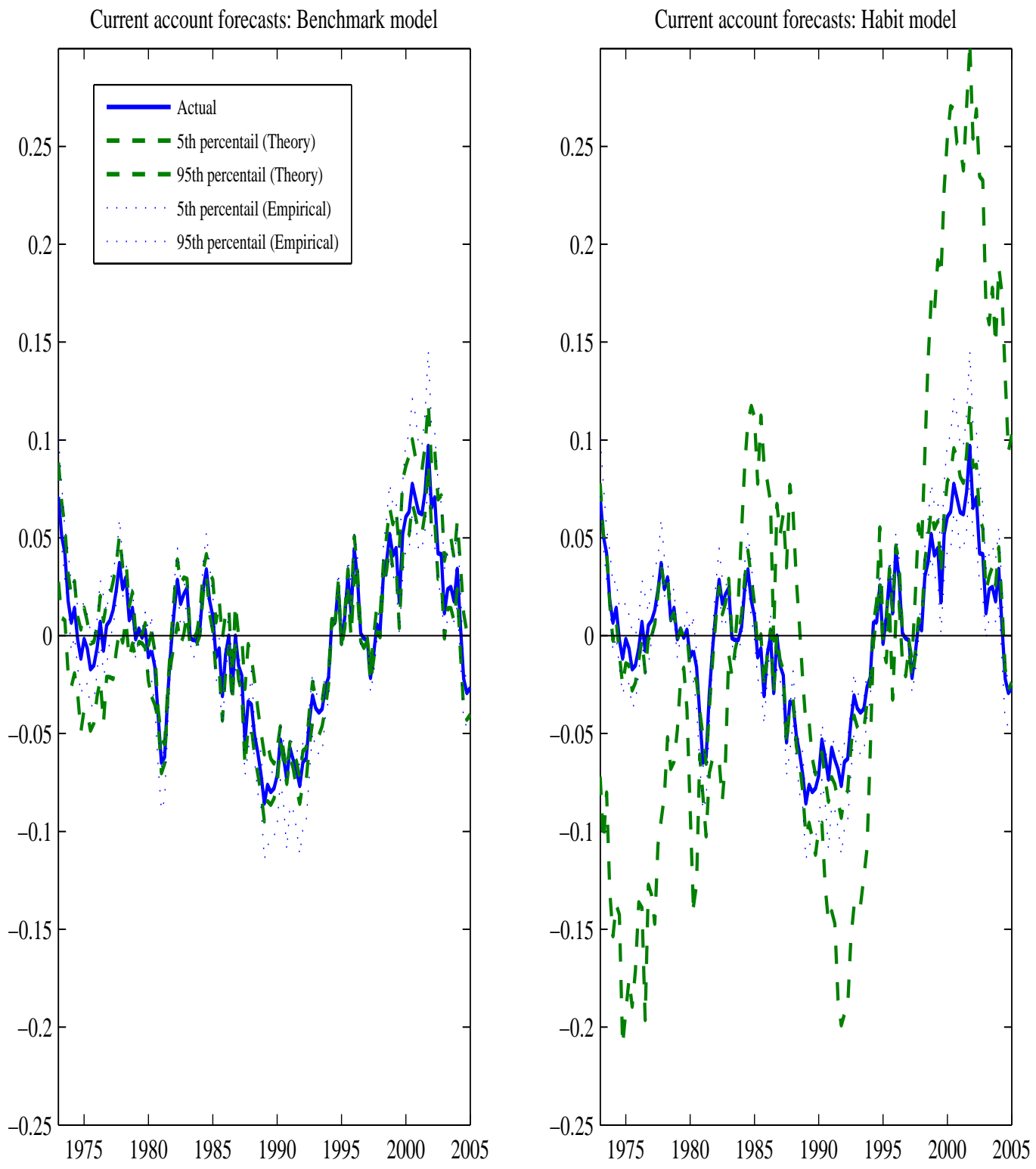
Figure 4(a): Theoretical Distributions of $m_{h}$ and $m_{J}$ : United Kingdom
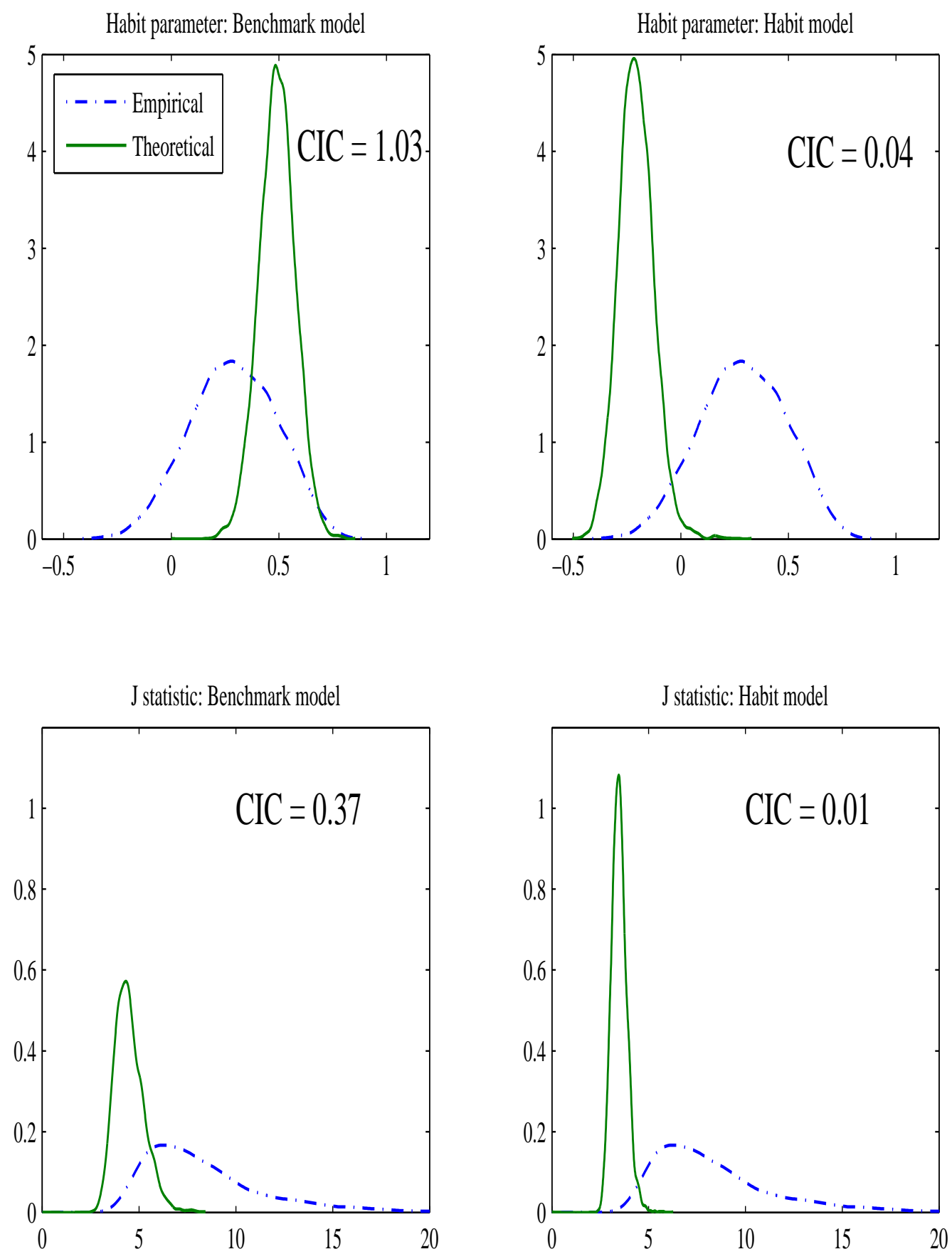
Figure 4(b): Theoretical Distributions of $\mathrm{m}_{c a, t}$ : United Kingdom
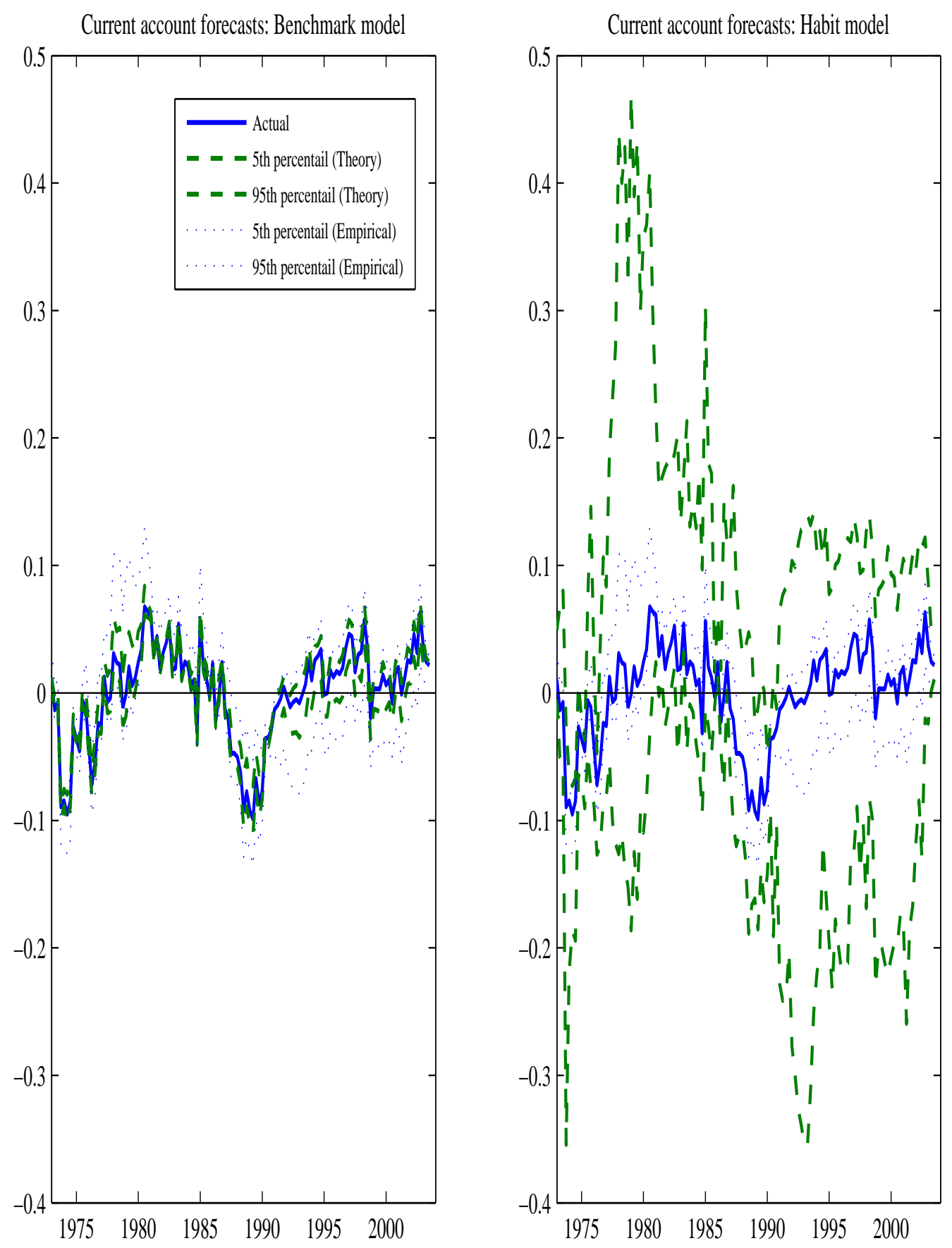